\title{
Effects of atypical antipsychotic drugs on QT interval in patients with mental disorders
}

\author{
Wilbert S. Aronow ${ }^{1}$, Tatyana A. Shamliyan ${ }^{2}$ \\ ${ }^{1}$ Department of Cardiology, Westchester Medical Center, New York Medical College, Valhalla, NY, USA; ${ }^{2}$ Quality Assurance, Evidence-Based \\ Medicine Center, Elsevier, Philadelphia, PA, USA \\ Contributions: (I) Conception and design: All authors; (II) Administrative support: TA Shamliyan; (III) Provision of study materials or patients: TA \\ Shamliyan; (IV) Collection and assembly of data: TA Shamliyan; (V) Data analysis and interpretation: All authors; (VI) Manuscript writing: All \\ authors; (VII) Final approval of manuscript: All authors. \\ Correspondence to: Tatyana A. Shamliyan, MD, MS. Quality Assurance, Evidence-Based Medicine Center, Elsevier, 1600 JFK Blvd, Philadelphia, PA \\ 19103, USA. Email: t.shamliyan@elsevier.com.
}

Background: Drug-induced QT prolongation is associated with higher risk of cardiac arrhythmias and cardiovascular mortality. We investigated the effects of atypical antipsychotic drugs on QT interval in children and adults with mental disorders.

Methods: We conducted random-effects direct frequentist meta-analyses of aggregate data from randomized controlled trials (RCT) and appraised the quality of evidence using the Grading of Recommendations Assessment, Development and Evaluation (GRADE) methodology. Our search in PubMed, EMBASE, the Cochrane Library, clinicaltrials.gov, and PharmaPendium up to October 2017 identified studies that examined aripiprazole, quetiapine, risperidone, olanzapine, ziprasidone and brexpiprazole.

Results: Low quality evidence suggests that aripiprazole (four meta-analyses and twelve RCTs), brexpiprazole (one systematic review and four RCTs) or olanzapine (five meta-analyses and twenty RCTs) do not increase QT interval. Low quality evidence suggests that ziprasidone (five meta-analyses and 11 RCTs) increases QT interval and the rates of QT prolongation while risperidone (four meta-analyses, 70 RCTs) and quetiapine (two meta-analyses and seven RCTs) are associated with QT prolongation and greater odds of torsades de pointes ventricular tachycardia especially in cases of drug overdose.

Conclusions: The main conclusion of our study is that in people with mental disorders and under treatment with atypical antipsychotic drugs, in order to avoid QT prolongation and reduce the risk of ventricular tachycardia clinicians may recommend aripiprazole, brexpiprazole or olanzapine in licensed doses. Long-term comparative safety needs to be established.

Keywords: Quality of evidence; cardiovascular morbidity; drug-induced QT prolongation; aripiprazole; quetiapine; risperidone; olanzapine; ziprasidone; brexpiprazole

Submitted Nov 24, 2017. Accepted for publication Mar 07, 2018.

doi: 10.21037/atm.2018.03.17

View this article at: http://dx.doi.org/10.21037/atm.2018.03.17

\section{Introduction}

Observational studies provide consistent evidence that prolonged QT interval is associated with higher risk of all-cause and cardiovascular mortality (1). Drug-induced prolongation of QT contributes to higher mortality $(2,3)$.
The risk of drug-induced prolongation of QT is much higher in older adults and people with multiple chronic conditions (4). Psychotropic drugs including atypical antipsychotic agents are commonly prescribed for licensed and off-label indications and may contribute to the higher risk of drug-induced QT prolongation $(5,6)$. This rapid 
review focuses on the effects of atypical antipsychotic drugs on QT interval in children and adults with mental disorders.

\section{Methods}

We used a standard recommended methodology in conducting systematic literature reviews and meta-analyses from the Cochrane Collaboration and the Agency for Healthcare Research and Quality $(7,8)$. We developed a priori protocol for a systematic literature review to answer the clinical question about the safety of atypical antipsychotic drugs on QT interval in children and adults with mental disorders.

We defined the target population as people with mental disorders treated with atypical antipsychotic drugs. Eligible interventions included atypical antipsychotics when compared with placebo or other antipsychotic medications. Eligible outcomes included change in QT Interval, clinically important prolongation of QT corrected to RR interval $\geq 450 \mathrm{msec}$ in men $\geq 480 \mathrm{msec}$ in women, and QTc $\geq 500 \mathrm{msec}$ associated with increased risk of life-threatening torsades de pointes ventricular tachycardia (9).

We conducted a comprehensive search in PubMed, EMBASE, the Cochrane Library, www.clinicaltrials.gov and PharmaPendium (www.pharmapendium.com) up to October 2017 to find systematic reviews, published and unpublished RCTs, and nationally represented controlled observational studies that reported adjusted effect estimates $(7,8)$. All of the authors determined the studies' eligibility. All citations found during the searches are stored in a reference database.

The data was extracted from the Clinical Trials Transformation Initiative (CTTI) (https://www.ctticlinicaltrials.org/aact-database), checked for quality, and stored in the HPCC platform (High-Performance Computing Cluster, https://hpccsystems.com/).

We performed direct frequentist meta-analyses of aggregate data when definitions of the active and control intervention and patient outcomes were deemed similar for pooling (10). We used random effects models to address inevitable differences in patient characteristics across primary RCTs. For each abstracted hypothesis, we calculated absolute risk difference and relative risk with $95 \%$ CI. We calculated number needed to treat and number of attributable events per 1,000 treated with 95\% CI based on statistically significant differences in absolute risks of the outcomes. We examined consistency in results across studies with chi-square tests and $\mathrm{I}^{2}$ statistics and concluded statistically significant heterogeneity if $\mathrm{I}^{2}$ was $>50 \%$ (7). Statistically significant heterogeneity did not preclude statistical pooling (10). However, we planned exploring heterogeneity with a priori defined patient characteristics, drug doses, and study quality if this information was available in the studies (10).

We used consensus method guidelines for systematic review and meta-analyses that do not recommend conducting post hoc analyses of statistical power (11-14). Instead, we downgraded our confidence in true treatment effects based on calculated optimal information size as the number of patients required for an adequately powered individual trial (15). Since power is more closely related to number of events than to sample size, we concluded imprecision in treatment effects if fewer than 250 patients experienced the event (15).

We used Statistics/Data Analysis, STATA software (StataCorp LP, College Station, Texas). Statistical significance was evaluated at a $95 \%$ confidence level.

We evaluated the quality of systematic reviews using the Assessment of Multiple Systematic Reviews (AMSTAR) (16). For primary RCTs, we used the Cochrane risk of bias tool on a 3-point scale: high bias, low bias, and unclear $(17,18)$. A low risk of bias was assumed when RCTs met all the riskof-bias criteria, a medium risk of bias if at least 1 of the riskof-bias criteria was not met, and a high risk of bias if two or more risk-of-bias criteria were not met. An unknown risk of bias was assigned for the studies with poorly reported risk-of-bias criteria. We assigned high risk of bias to all observational studies.

The authors assigned the quality of evidence ratings as high, moderate, low, or very low, according to risk of bias in the body of evidence, directness of comparisons, precision and consistency in treatment effects, and the evidence of reporting bias, using Grading of Recommendations Assessment, Development and Evaluation (GRADE) methodology (19).

A high quality of evidence was assigned to well-designed RCTs with consistent findings. The quality of evidence was downgraded to moderate if at least 1 of 4 quality of evidence criteria was not met; for example, moderate quality of evidence was assigned if there was a high risk of bias in the body of evidence or if the results were not consistent or precise. The quality of evidence was downgraded to low if two or more criteria were not met. We concluded a high risk of bias in the body of evidence if at least one RCT had high risk of bias. We downgraded the quality of evidence 
when we suspected high risk of publication bias due to unavailability of the results in clinicaltrials.gov or journal articles.

A low quality of evidence was assigned to nonrandomized studies, but the rating was upgraded if there was a strong or dose-response association (20). Evidence was defined as insufficient when no studies provided valid information about treatment effects. This approach was applied regardless of whether the results were statistically significant.

\section{Results}

Our comprehensive search in PubMed, EMBASE, the Cochrane Library, and clinicaltrials.gov up to May 2017 identified clinical studies that examined aripiprazole, quetiapine, risperidone, olanzapine, ziprasidone or brexpiprazole.

Risperidone was examined in three systematic reviews and meta-analyses, one individual patient data network meta-analysis of 64 RCTs, published and unpublished data from six RCTs and six non-randomized studies (21-40).

Evidence suggests that risperidone is associated with QT prolongation in children and adolescents with mental disorders (Table 1).

A single industry-sponsored individual patient metaanalysis of 64 RCTs suggests that risperidone results in QT prolongation when compared with placebo in adults with mental disorders (Table 1). The evidence from the FDA Adverse Event Reporting System database suggests that risperidone is associated with greater odds of torsades de pointes ventricular tachycardia in adults with indication for antipsychotics (Table 1). Industry-sponsored postmarketing analysis suggests that all cases of ventricular tachycardia have been associated with overdose of risperidone (41).

The direct evidence of comparative safety between risperidone and other antipsychotics is sparse. Risperidone is associated with QT abnormalities when compared with aripiprazole in pediatric patients with mental disorders and concomitant use of stimulants (Table 2). Some evidence suggests that there are no differences in QT abnormalities or rates of torsades de pointes between risperidone and atypical antipsychotics or haloperidol in adults with mental disorders (Table 2). A single RCT suggests that risperidone decreases QT interval when compared with ziprasidone (Table 2).

Post-marketing surveillance suggests 43 cases of prolonged QT intervals and 71 cases of torsades de pointes tachycardia in people treated with risperidone among other medications for various mental disorders (Table S1).

Ziprasidone was examined in four systematic reviews and meta-analyses, one industry sponsored individual patient data network meta-analysis and published and unpublished data from 11 RCTs and three non-randomized trials $(30,35,37,38,42-56)$.

Evidence suggests that ziprasidone increases QT interval and the rates of QT prolongation by $>30 \mathrm{msec}$ when compared with placebo (Table 3) or haloperidol (Table 4) in people with mental disorders. Ziprasidone also prolongs QT interval when compared with olanzapine and risperidone (Table 5). There are no differences in the length of QT interval after treatment with ziprasidone versus aripiprazole (Table 5). Chlorpromazine increases the duration of QT interval when compared with ziprasidone (Table 5).

Available studies did not report the rates of torsade de pointes ventricular tachycardia in adults treated with ziprasidone. Post-marketing observational study suggested no differences in mortality after 1 -year treatments with ziprasidone versus olanzapine in 18,154 adults with schizophrenia (Table S2). Post-marketing surveillance identified 202 cases of prolonged QT interval and 83 cases of torsade de pointes in patients treated with ziprasidone among other drugs (Table S1).

The evidence is applicable mostly to adults. Pediatric studies reported no events of QT prolongation after higher $(160 \mathrm{mg} /$ day $)$ or lower $(20 \mathrm{mg} / \mathrm{d}$ titrated to between $80 \mathrm{mg} /$ day) doses on ziprasidone $(37,42)$.

Olanzapine was examined in four systematic reviews and meta-analyses and one individual patient data network meta-analysis. $(35,37,38,57,58)$. We also identified published and unpublished data from 20 RCTs and 1 non-randomized trial (30,43,59-79).

Available low-quality evidence suggests that olanzapine has no effect on QT interval when compared with placebo in children and adolescents with mental disorders (Table 6). We also found that that oral olanzapine has no effect on QT interval while intramuscular olanzapine decreases QT interval when compared with placebo in adults with mental disorders (Table 6).

A single small RCT suggests that there are no differences in QT interval between olanzapine and haloperidol in children and adolescents with autistic disorder (Table 7). Moderate quality evidence suggests that there are no differences in QT interval between olanzapine and 


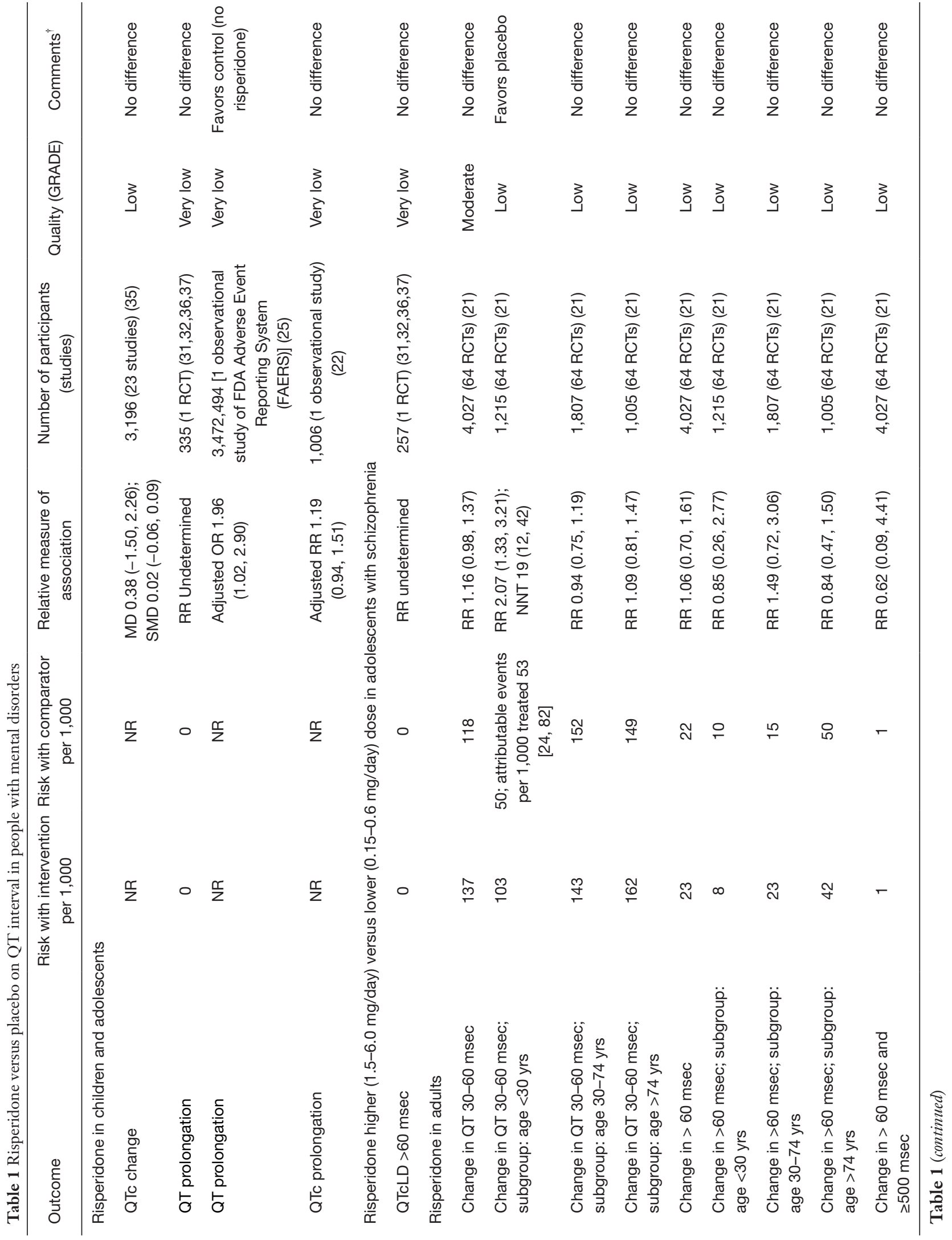




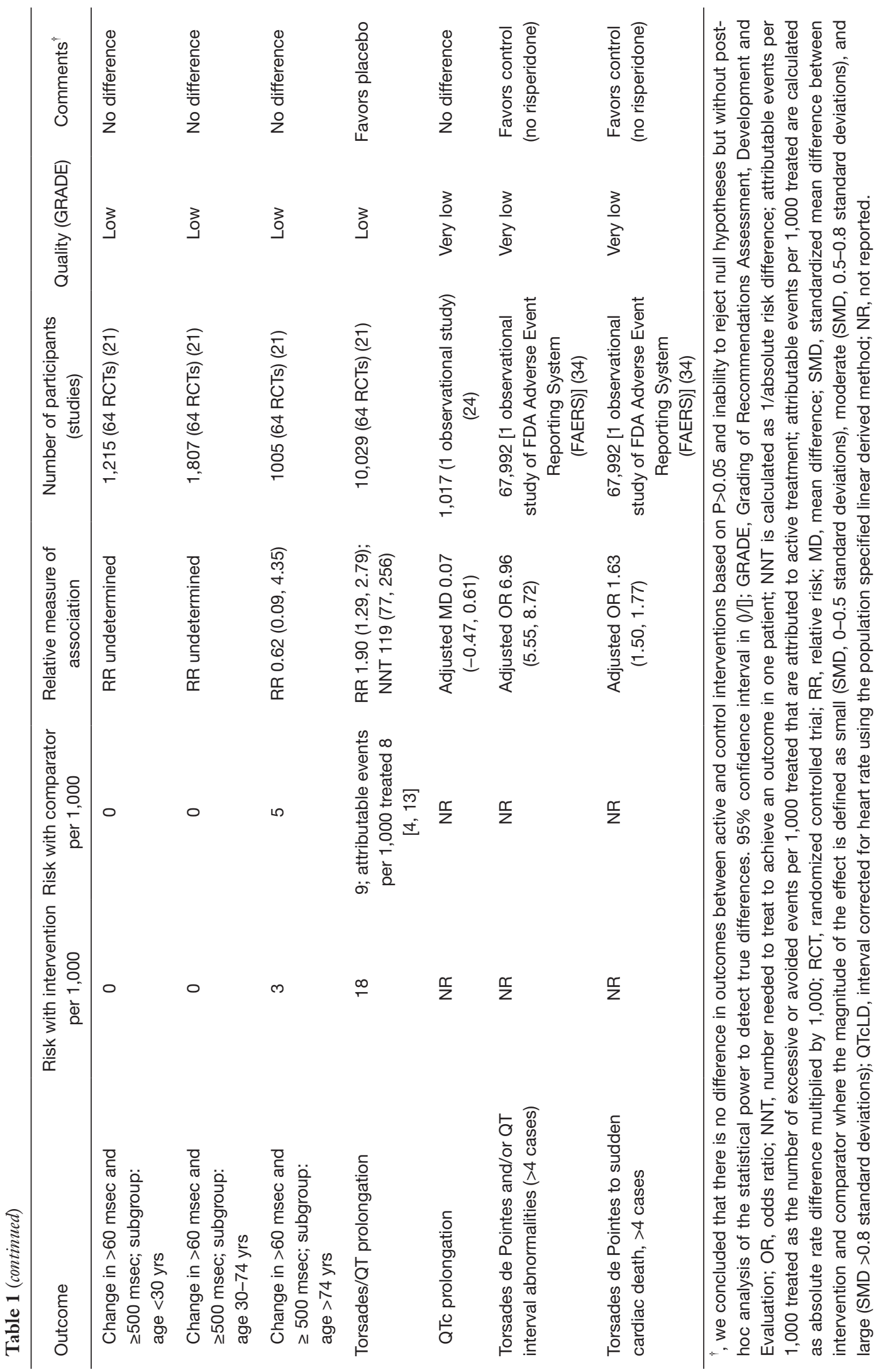


Table 2 Risperidone versus active comparators on QT interval in people with mental disorders

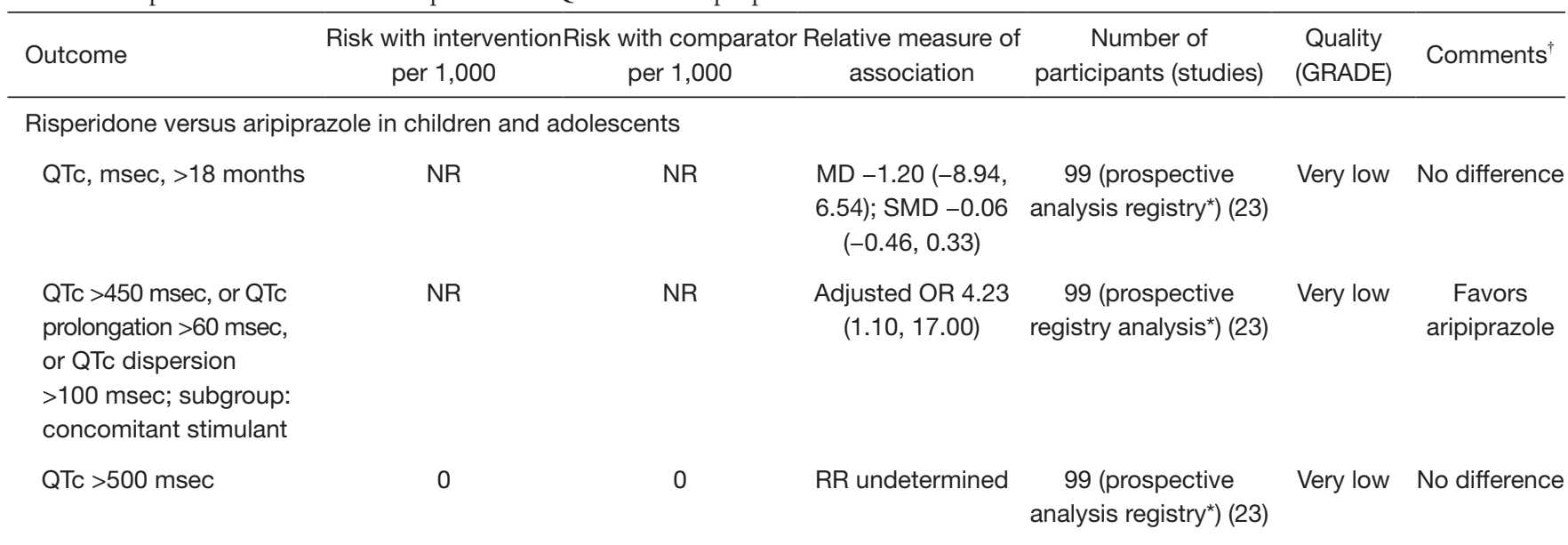

Risperidone long-acting Injection versus oral atypical antipsychotics (olanzapine, quetiapine, aripiprazole or amisulpride) in adults

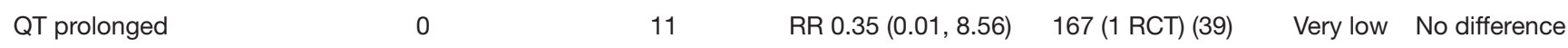

Risperidone or paliperidone versus active control in adults

$\begin{array}{llllll}\begin{array}{l}\text { Torsades/QT } \\ \text { prolongation }\end{array} & 18 & 19 & \text { RR } 0.94(0.59,1.51) & 7,573(64 \text { RCTs })(21) & \text { Very low No difference }\end{array}$

Risperidone $16 \mathrm{mg} / \mathrm{d}$ versus haloperidol $15 \mathrm{mg} / \mathrm{d}$ in adults
QTc $>500$ msec
0
0
RR Undetermined
$52(1 \mathrm{RCT})(30,38)$
Very low No difference

Risperidone $4 \mathrm{mg}$ versus risperidone, $2 \mathrm{mg} / \mathrm{d}$ + Haloperidol, $2 \mathrm{mg} / \mathrm{d}$ in adults
QTc, msec
NR
NR
MD $-1.49(-14.77$, 11.79); SMD -0.06
$(-0.57,0.46)$
$58(1 \mathrm{RCT})(28,29)$
Very low No difference

Risperidone versus olanzapine in adults

$\begin{array}{lcccc}\begin{array}{l}\text { Torsades de Pointes, } \\ \text { sudden cardiac death }\end{array} & \text { NR } & \text { Adjusted HR } 1.04 & 459,614 & \text { Very low } \\ & & (0.88,1.24) & \text { No difference } \\ \text { (1 observational study } & \end{array}$

Risperidone versus ziprasidone in adults

$\begin{array}{cccc}\text { QTC NR } \quad \text { NR } & \text { MD }-21.80(-28.13,24(1 \mathrm{RCT})(26,27) \quad \text { Very low Favors } \\ & -15.47) ; \mathrm{SMD}-2.76 & (-3.90,-1.62)\end{array}$

\footnotetext{
*, SafEty of NeurolepTics in Infancy and Adolescence (SENTIA) registry (https://sentia.es). ${ }^{\dagger}$, we concluded that there is no difference in outcomes between active and control interventions based on $\mathrm{P}$ value $>0.05$ and inability to reject null hypotheses but without posthoc analysis of the statistical power to detect true differences. 95\% confidence interval in ( ); GRADE, Grading of Recommendations Assessment, Development and Evaluation; OR, odds ratio; NNT, number needed to treat to achieve an outcome in one patient; NNT is calculated as 1/absolute risk difference; attributable events per 1,000 treated as the number of excessive or avoided events per 1000 treated that are attributed to active treatment; attributable events per 1,000 treated are calculated as absolute rate difference multiplied by 1,000; RCT, randomized controlled trial; RR, relative risk; MD, mean difference; SMD, standardized mean difference between intervention and comparator where the magnitude of the effect is defined as small (SMD, 0-0.5 standard deviations), moderate (SMD, 0.5-0.8 standard deviations), and large (SMD >0.8 standard deviations); QTc, corrected QT interval; NR, not reported.
} 


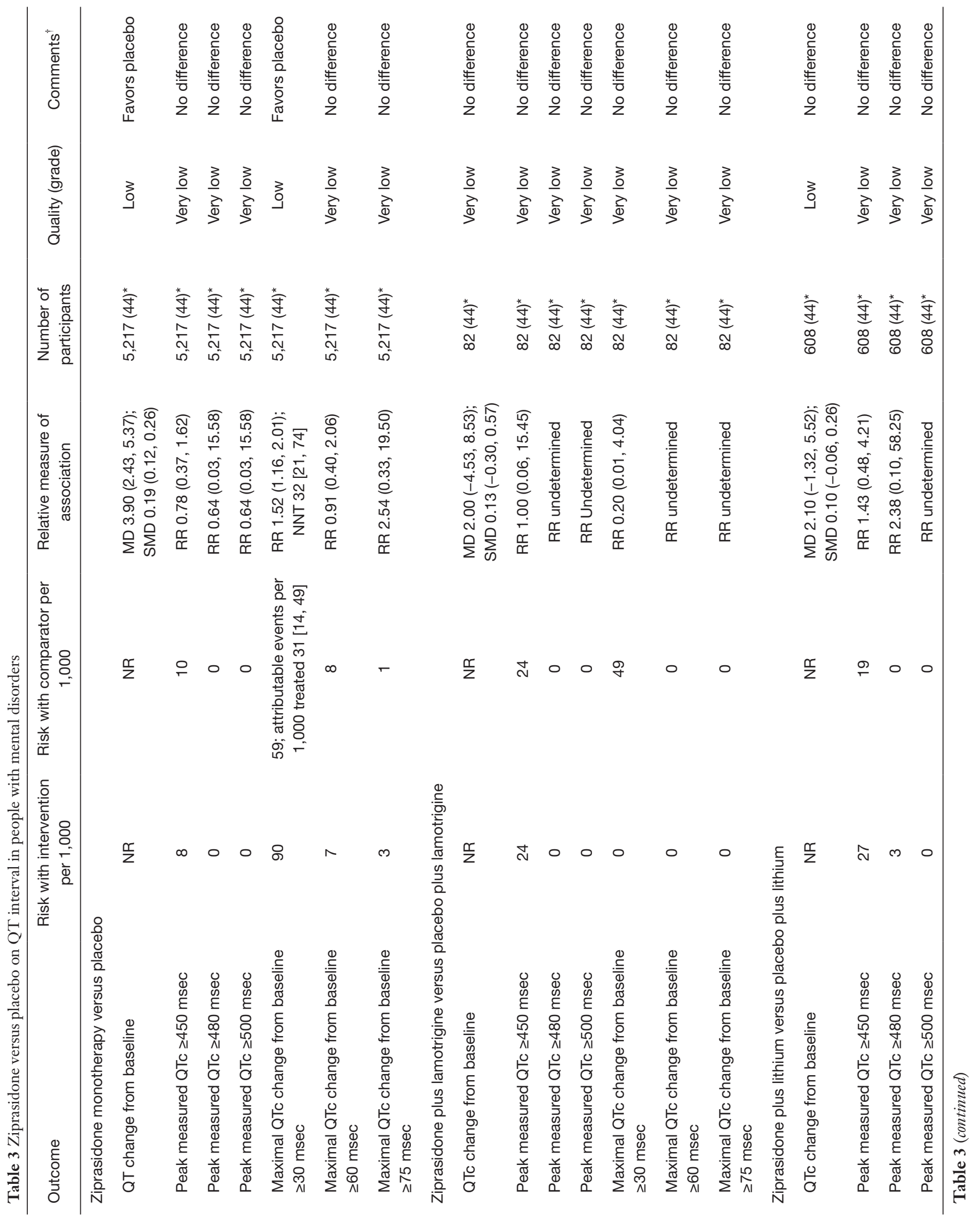




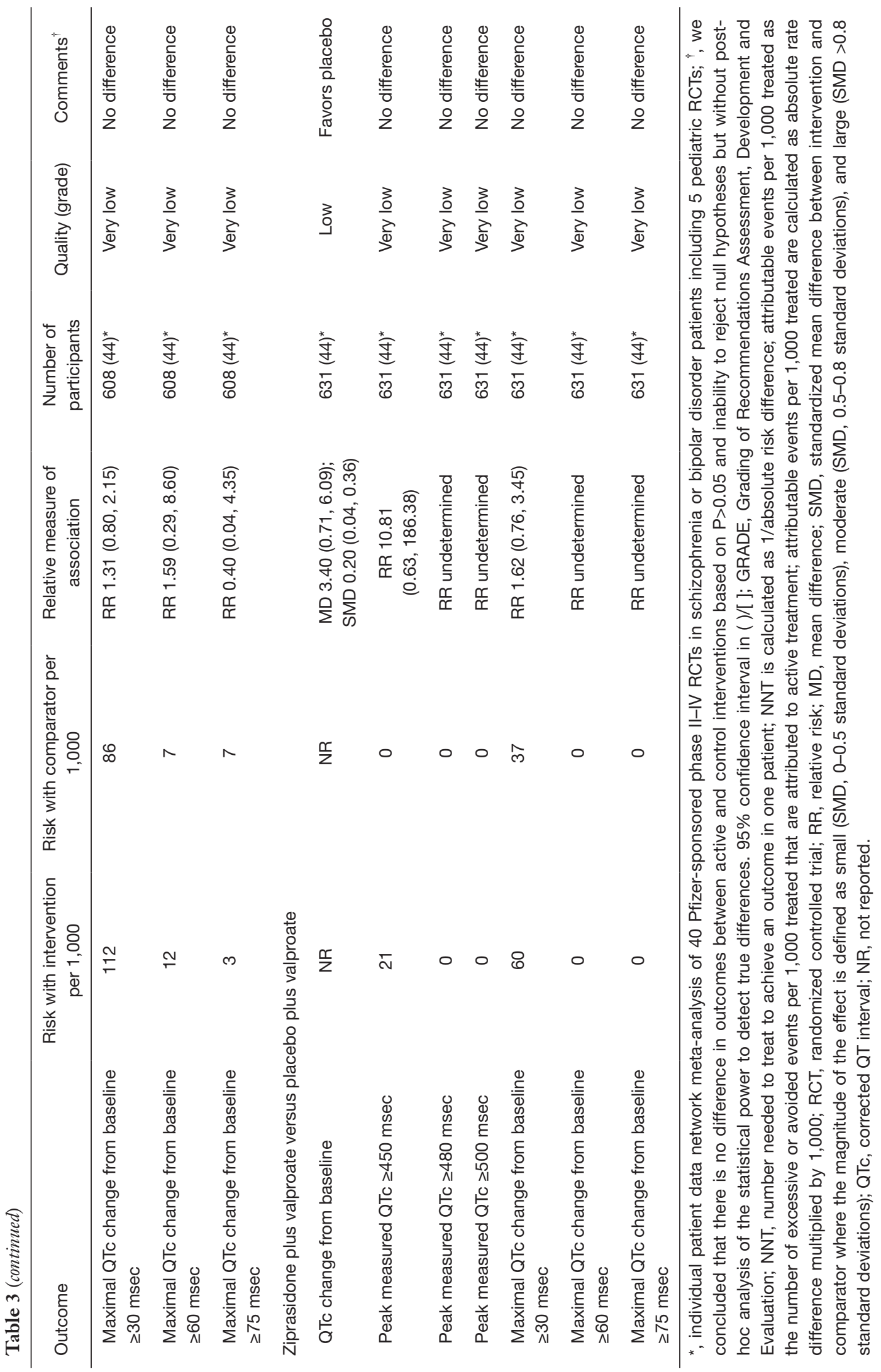




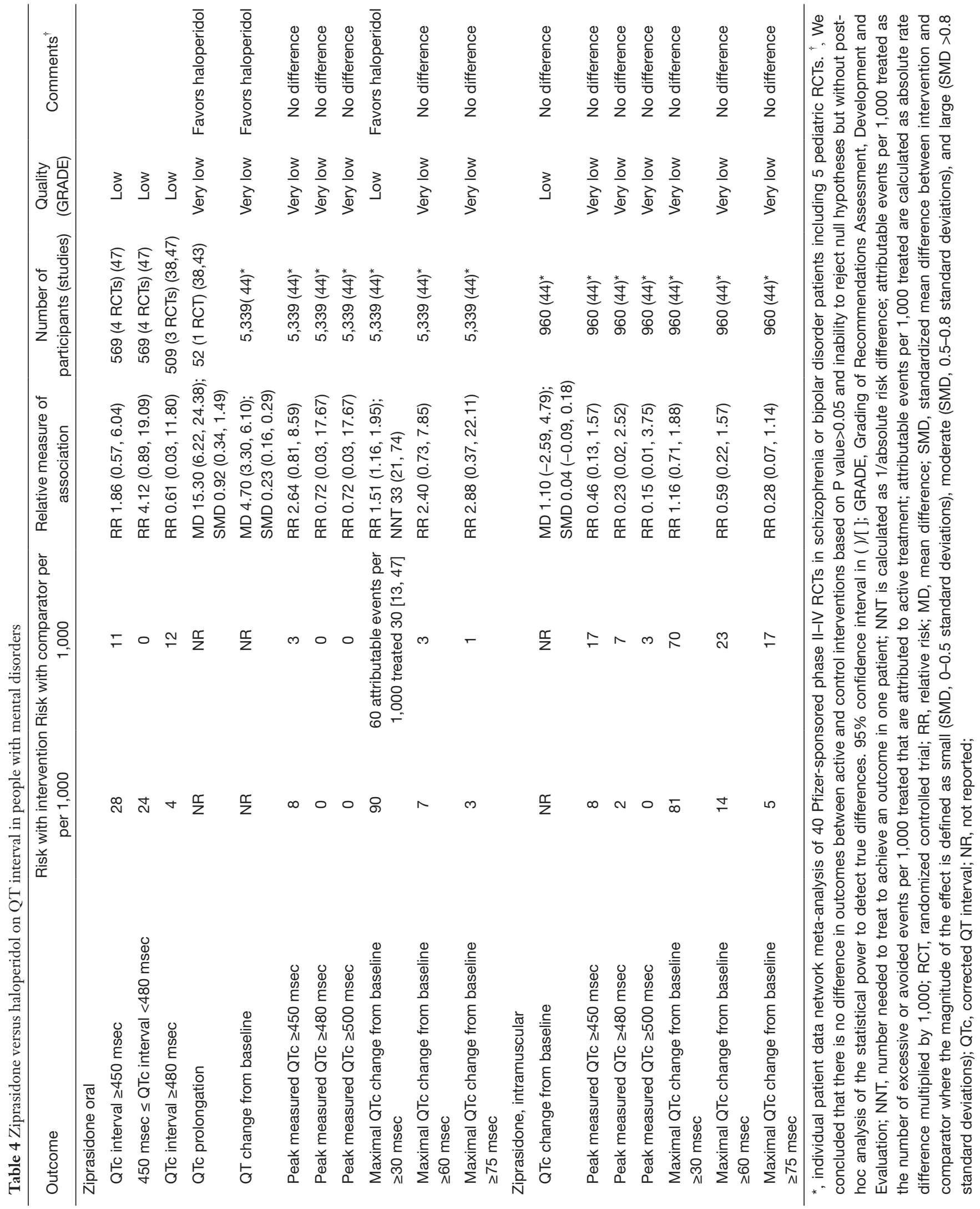




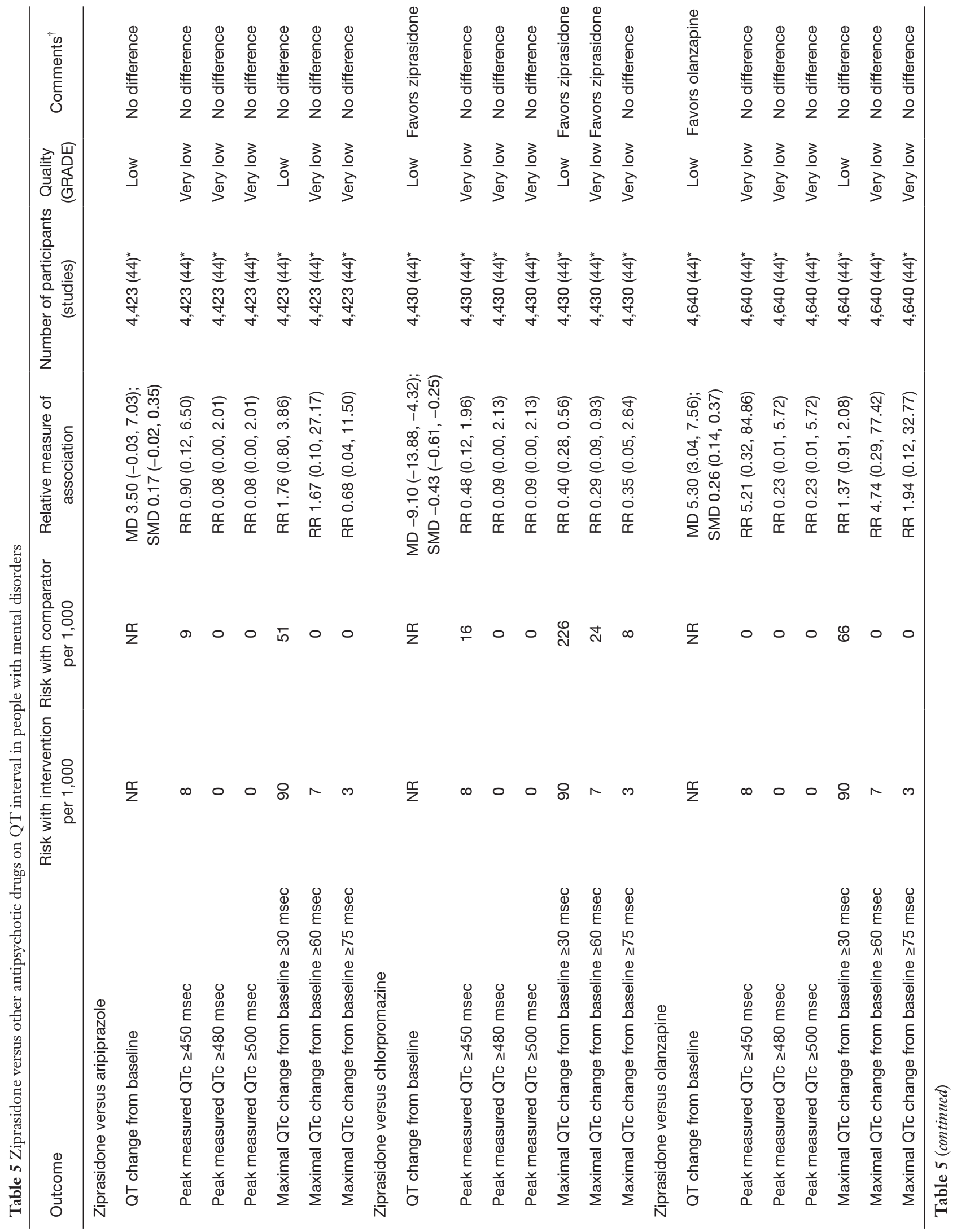




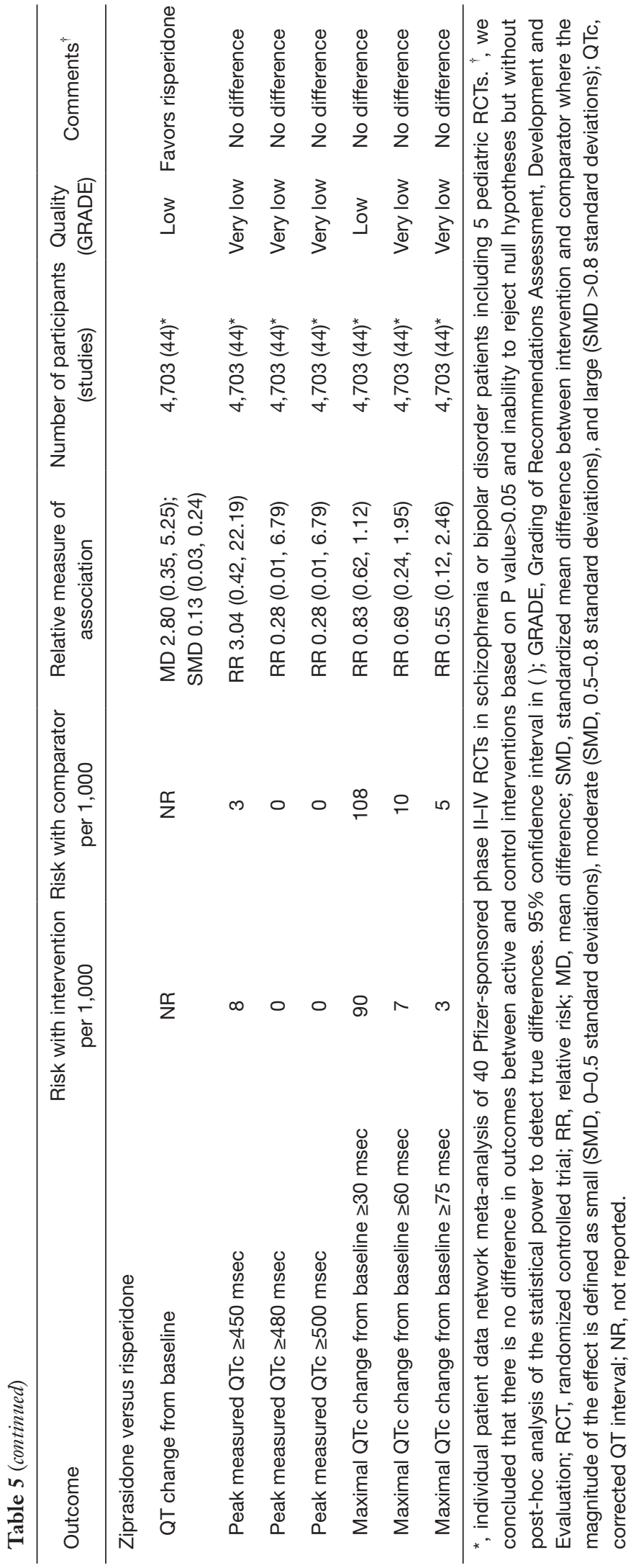




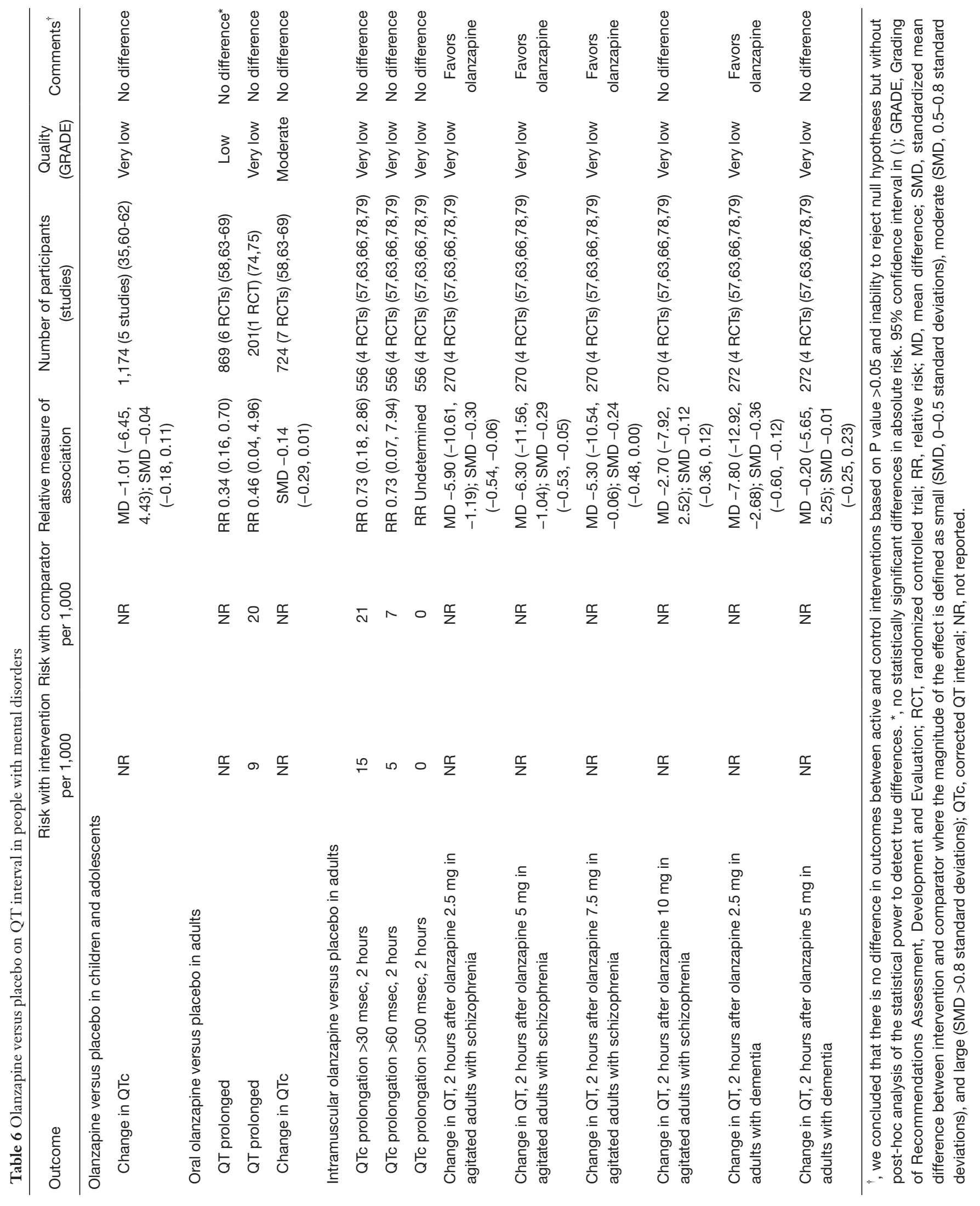




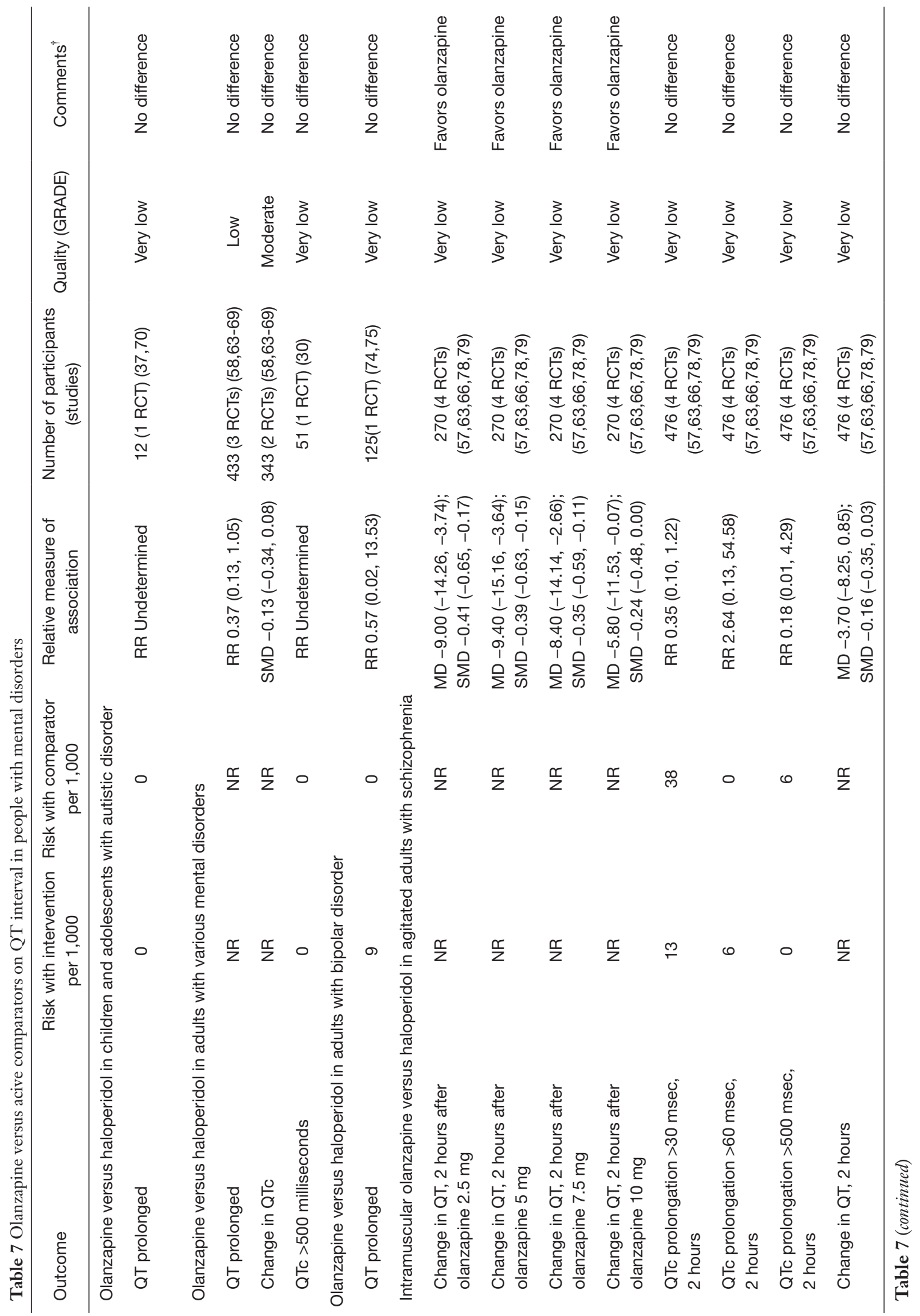




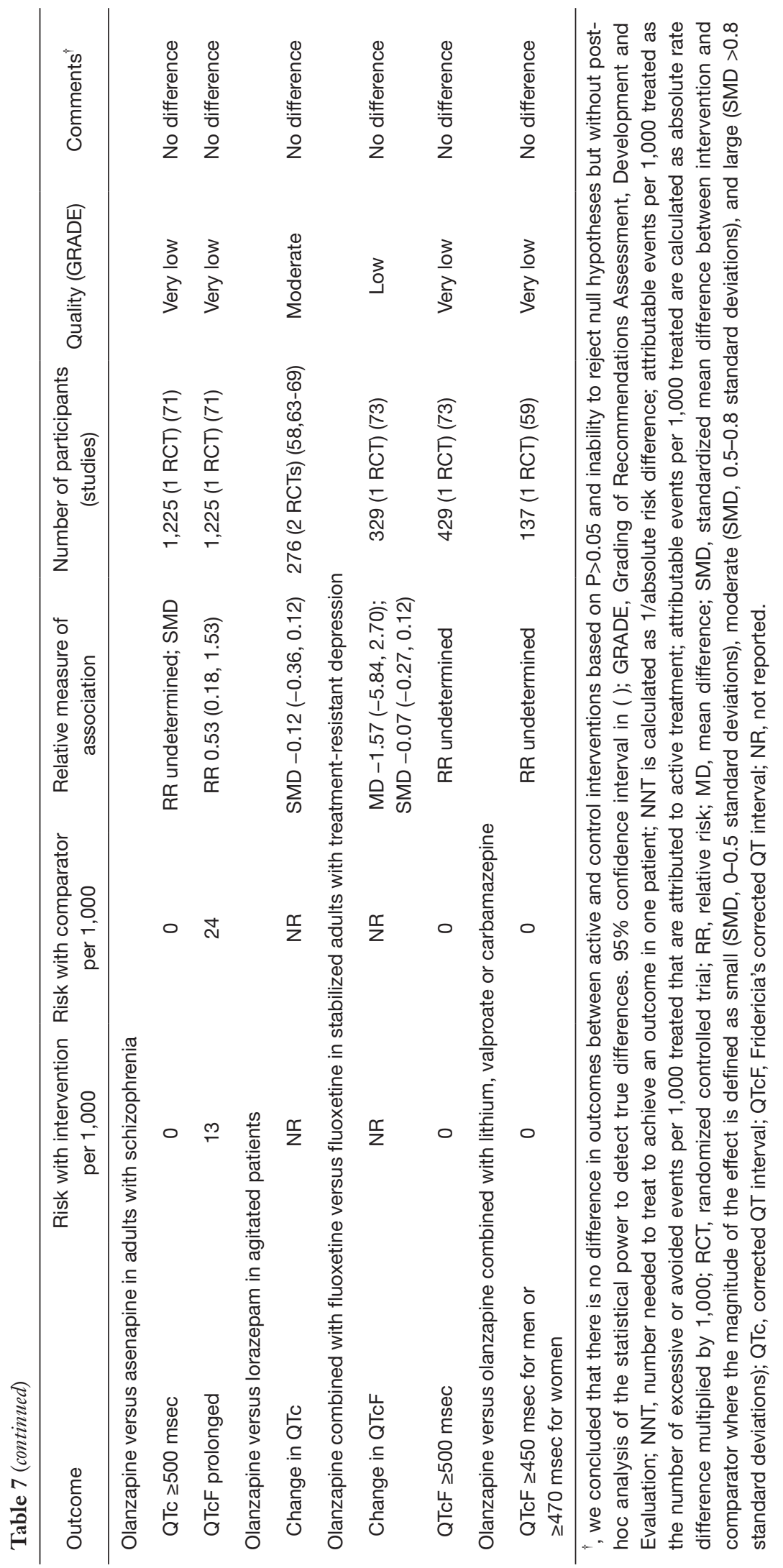


haloperidol, asenapine, or lorazepam in adults with mental disorders (Table 7). Intramuscular olanzapine decreases QT interval when compared with haloperidol in agitated adults (Table 7).

Post-marketing surveillance suggests 84 cases of prolonged QT intervals and 53 cases of torsades de pointes tachycardia in people treated with olanzapine among other medications for various mental disorders (Table S1).

Quetiapine was examined in two systematic reviews and meta-analyses $(38,80)$. We also identified published and unpublished data from 7 RCTs and 4 non-randomized studies (21-40,81-86).

When compared with placebo or no active treatment, evidence suggests that quetiapine is not associated with the risk of QT prolongation in children and adolescents (Table 8). In contrast, quetiapine is associated with higher odds of torsade's de pointes or QT interval abnormalities in adult patients with mental disorders (Table 8).

When compared with other antipsychotics, sparse evidence suggests that there are no differences in QT interval between quetiapine and haloperidol or risperidone (Table 9). Sparse data from a single RCT suggests that quetiapine decreases QT interval when compared with ziprasidone in adults with mental disorders (Table 9). Observational analysis of Medicaid database demonstrates that quetiapine is associated with the lower risk of torsade's de pointes or sudden cardiac death when compared with olanzapine (Table 9).

Post-marketing surveillance suggests 56 cases of prolonged QT intervals and 90 cases of torsade's de pointes tachycardia in people treated with olanzapine among other medications for various mental disorders (Table S1).

Aripiprazole was examined in four systematic reviews and meta-analyses and published and unpublished data from 12 RCTs and three non-randomized trials (35-37,60-62,87-97).

Evidence suggests that there are no differences in QT interval changes or rates of prolonged QT interval between aripiprazole and placebo, risperidone or haloperidol in adults with mental disorders (Table 10). Higher dose of aripiprazole does not increase QT interval when compared with the lower dose (Table 10). Available studies did not report the rates of torsade de pointes ventricular tachycardia in adults treated with aripiprazole. Post-marketing surveillance identified 15 cases of prolonged QT interval and 21 cases of torsade de pointes in patients treated with aripiprazole among other drugs (Table S1).

Sparse evidence suggests that aripiprazole is associated with reduction in QT interval in pediatric patients with mental disorders (Table 11). Sparse evidence suggests that there are no differences in the rates of prolonged QT interval between aripiprazole, placebo, risperidone or pimozide in children and adolescents with mental disorders (Table 11).

The evidence regarding the role of chronic inflammation or genetic polymorphism on QT interval in patients taking aripiprazole is insufficient (98-100).

Aripiprazole may present a safer choice in patients who need antipsychotic drugs and have no cardiac disorders associated with higher risk of cardiac death (101).

Brexpiprazole was examined in one systematic review and unpublished data from four RCTs (102-105).

Evidence suggests that there are no differences in the rates of the prolonged ( $>500 \mathrm{msec}$ or increase by $>60 \mathrm{msec}$ ) QT interval between brexpiprazole and placebo in adults with mental disorders (Table 12). Sparse evidence from a single unpublished RCT suggests that the lower $(4 \mathrm{mg})$ but not higher $(12 \mathrm{mg})$ dose of brexpiprazole prolongs QT interval when compared with placebo (Table 12). The evidence regarding effects of brexpiprazole on QT interval in children is insufficient. The evidence regarding comparative safety between brexpiprazole and other antipsychotics on QT interval or the risk of ventricular tachycardia is insufficient.

Post-marketing surveillance does not detect cases of prolonged QT intervals or torsades de pointes tachycardia in people treated with brexpiprazole among other medications for various mental disorders (Table S1).

\section{Discussion}

Our review of clinical trials, observational studies and postmarketing surveillance found mostly low quality of evidence concerning higher risk of antipsychotic drugs induced QT prolongation. In people with mental disorders referred for treatment with atypical antipsychotic drugs, in order to avoid QT prolongation and reduce the risk of ventricular tachycardia clinicians may recommend aripiprazole, brexpiprazole or olanzapine in licensed doses.

Our findings are in concordance with previously published observational studies that reported a positive association between antipsychotic drugs and the increased risk of cardiac arrest (106-108).

We downgraded the quality of evidence due to the high risk of bias and small number of events in the RCTs. The majority of clinical studies did not have statistical 


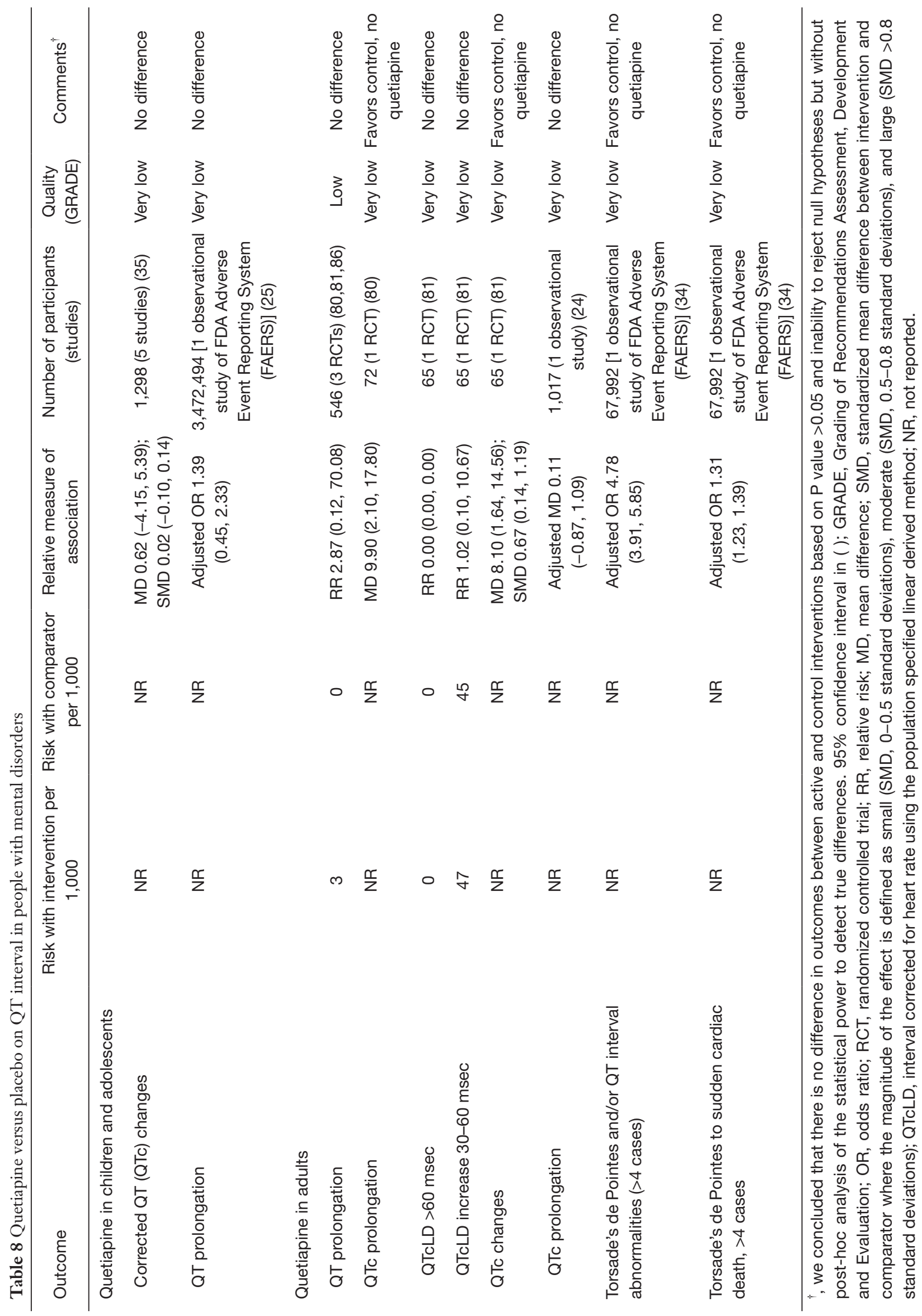




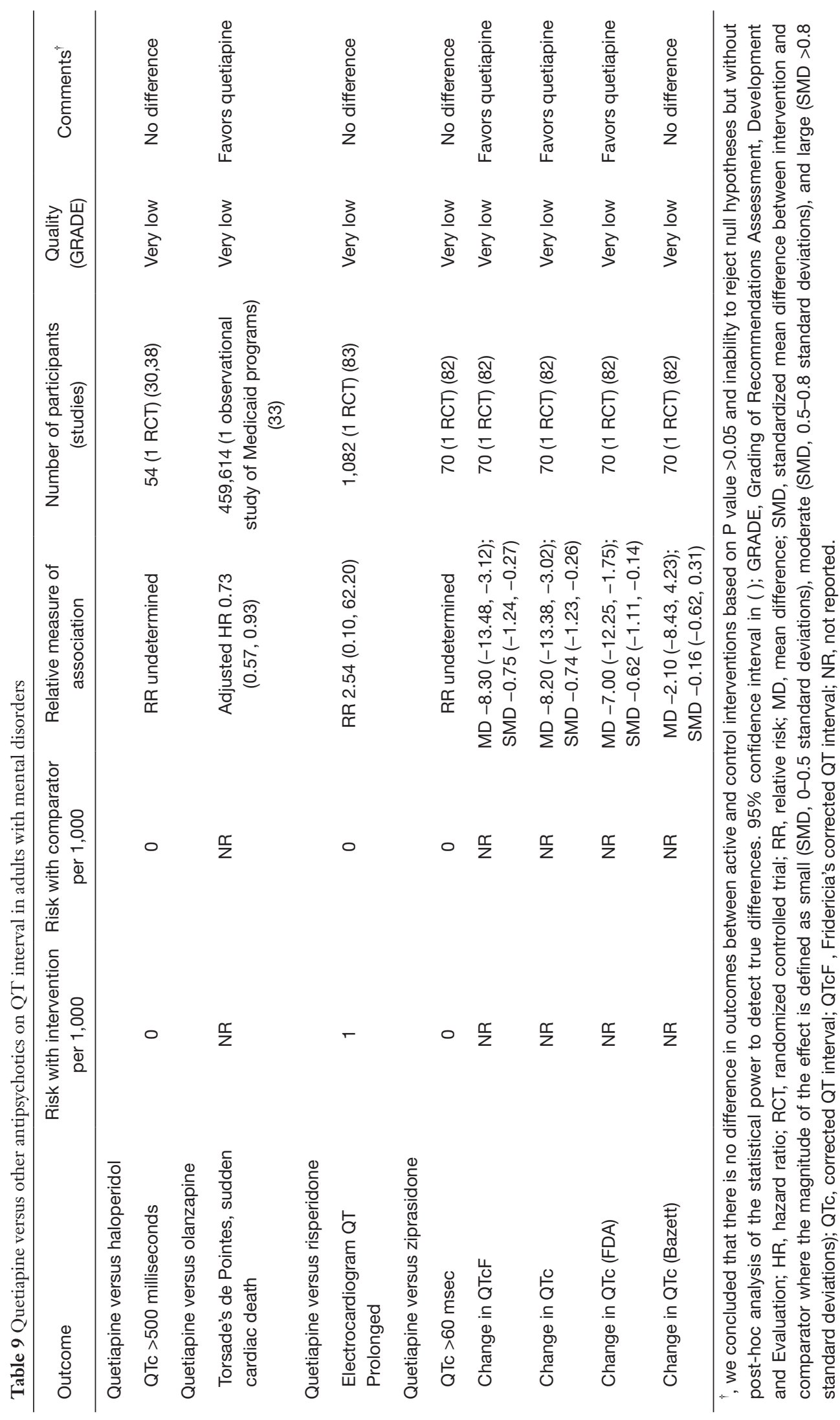




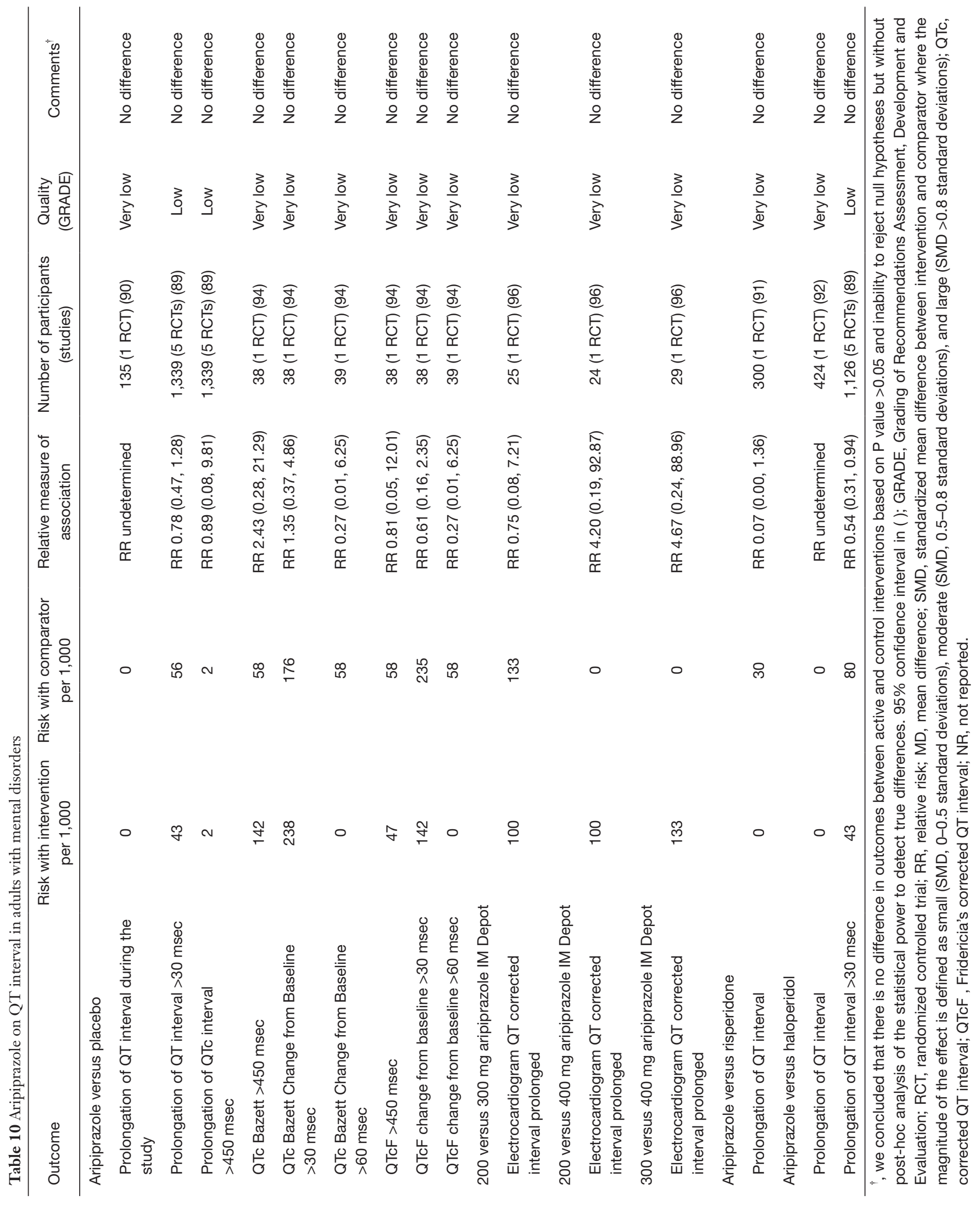




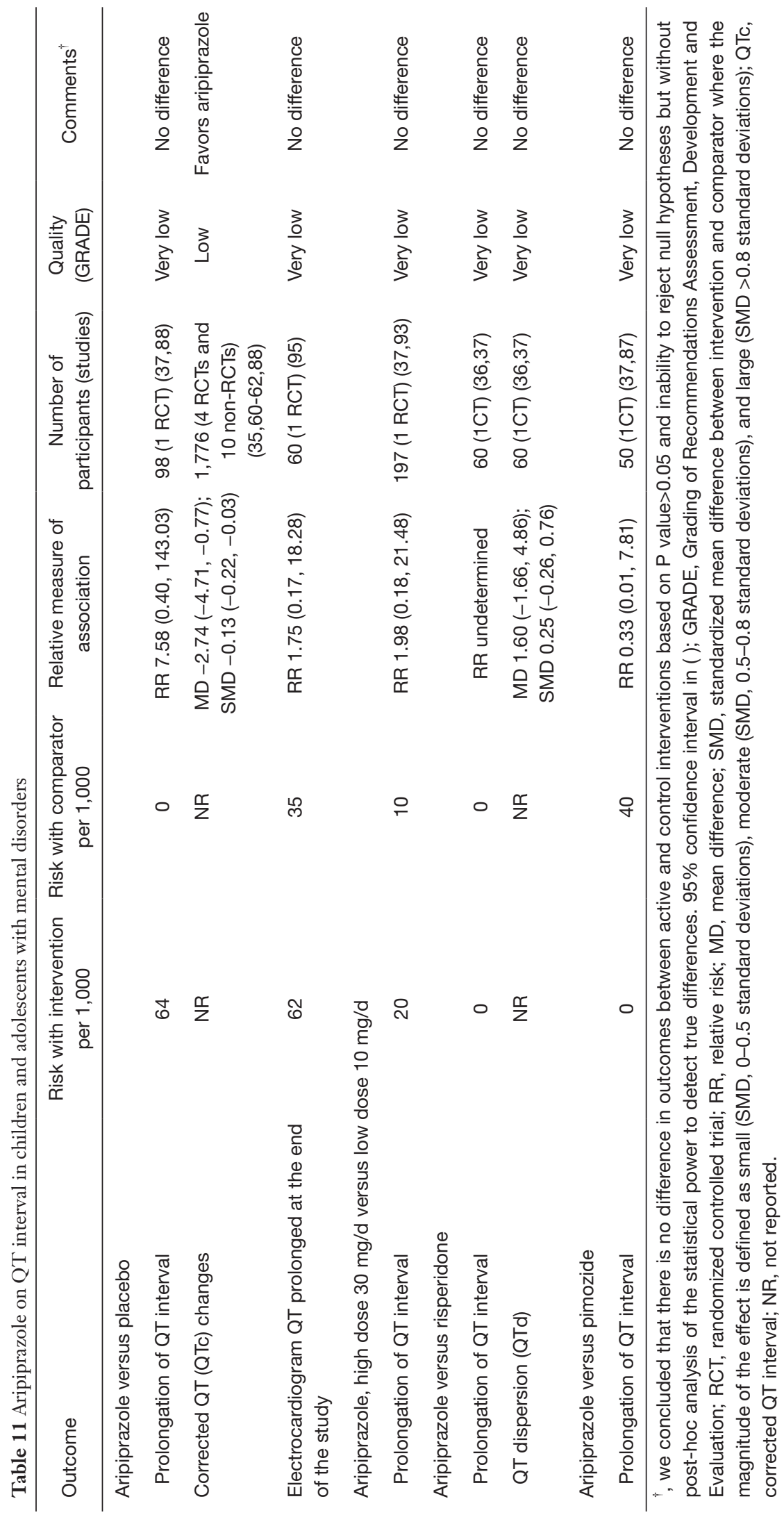




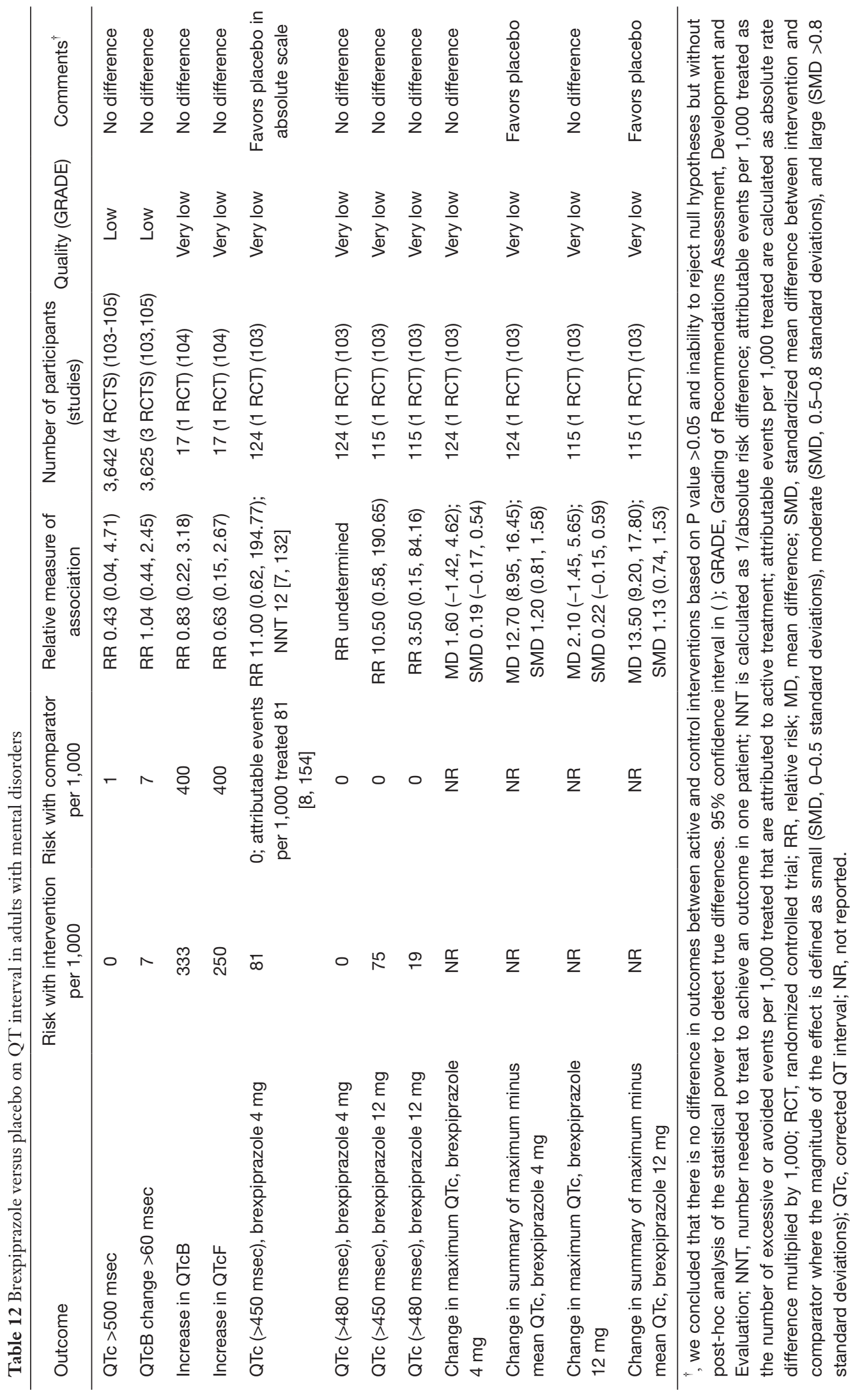


power to detect higher risk of ventricular tachycardia. We further downgraded the quality of evidence due to reporting bias because very small proportion of primary studies that examined benefits of atypical antipsychotics also examined drug-induced QT prolongation. Retrospective post-marketing case reports collection is biased because the reporting depends on clinician opinion regarding the association between ventricular tachycardia and administration of antipsychotic drugs (109).

Available industry guidelines recommend intensive ECG monitoring of QT intervals in clinical trials of non-antiarrhythmic drugs with suspected proarrhythmic potential but do not require proactive postmarketing monitoring in real-life settings (110). Some clinical guidelines recommend careful consideration of individual benefits and harms including drug-induced QT prolongation in people with mental disorders and indication for antipsychotic drugs (111-113). Only two British guidelines and one US guideline meet 2013 Institute of Medicine criteria for trustworthy guidelines (111-113). Drug labels recommend against administration of quetiapine or ziprasidone in combination with other drugs that are known to prolong QT interval and in people with bradycardia, hypokalemia or hypomagnesemia, congenital prolongation of the QT interval $(114,115)$. Despite these recommendations, prevalence of polypharmacy with multiple pro-arrhythmic drugs is high $(2,4,101)$.

Our review has implications for clinical practice. Clinicians should evaluate baseline risk for cardiac arrhythmias before offering atypical antipsychotic drugs (116). Routine ECG monitoring for the prolongation of QT interval should be recommended for all patients under the treatment with atypical antipsychotic drugs (117). Multidisciplinary coordinated care should be practiced to avoid polypharmacy with multiple pro-arrhythmic drugs $(116,118)$. Patients should be proactively examined for clinical symptoms indicating the occurrence of cardiac arrhythmias, e.g., dizziness, palpitations, or syncope (119). Our review has policy implications. Prescribing quality in compliance with licensed drug use should be routinely evaluated with electronic decision support systems. $(114,115,120)$. Proactive technologically advanced pharmacovigilance applications should be implemented to decrease the risk of drug-induced QT prolongation and cardiac arrhythmias (109,121-124).

Our review has research implications. Future proactive post-marketing surveillance should examine long-term comparative safety of atypical antipsychotic drugs in patients with different age, primary diagnosis and multiple comorbidities and concomitant drugs. Novel technology applications and adequate statistical methods should be used for routine analysis of antipsychotic-induced QT prolongation and cardiac arrhythmias.

\section{Acknowledgements}

This work is supported by Elsevier Evidence-based Medicine Center.

\section{Footnote}

Conflicts of Interest: The authors have no conflicts of interest to declare.

\section{References}

1. Zhang Y, Post WS, Blasco-Colmenares E, et al. Electrocardiographic QT interval and mortality: a metaanalysis. Epidemiology 2011;22:660-70.

2. Jackobson G, Carmel NN, Lotan D, et al. Reckless administration of QT interval-prolonging agents in elderly patients with drug-induced torsade de pointes. Z Gerontol Geriatr 2018;51:41-7.

3. Schächtele S, Tumena T, Gassmann KG, et al. CoPrescription of QT-interval prolonging drugs: an analysis in a large cohort of geriatric patients. PLoS One 2016;11:e0155649.

4. Franchi C, Ardoino I, Rossio R, et al. Prevalence and risk factors associated with Use of QT-prolonging drugs in hospitalized older people. Drugs Aging 2016;33:53-61.

5. Oteri A, Mazzaglia G, Pecchioli S, et al. Prescribing pattern of antipsychotic drugs during the years 19962010: a population-based database study in Europe with a focus on torsadogenic drugs. Br J Clin Pharmacol 2016;82:487-97.

6. Brooks M. 100 Best-selling, Most Prescribed Branded Drugs Through June. Medscape Medical News, WebMD, LLC 2015; Aug 13.

7. Higgins J, Green S, editors. Cochrane handbook for systematic reviews of interventions. Version 5.1.0. Cochrane book series. London: The Cochrane Collaboration, 2011.

8. Slutsky J, Atkins D, Chang S, et al. AHRQ series paper 1: comparing medical interventions: AHRQ and the effective health-care program. J Clin Epidemiol 2010;63:481-3.

9. Rabkin SW, Cheng XB. Nomenclature, categorization 
and usage of formulae to adjust QT interval for heart rate. World J Cardiol 2015;7:315-25.

10. Fu R, Gartlehner G, Grant M, et al. Conducting quantitative synthesis when comparing medical interventions: AHRQ and the Effective Health Care Program. J Clin Epidemiol 2011;64:1187-97.

11. Levine M, Ensom MH. Post hoc power analysis: an idea whose time has passed? Pharmacotherapy 2001;21:405-9.

12. Goodman SN, Berlin JA. The use of predicted confidence intervals when planning experiments and the misuse of power when interpreting results. Ann Intern Med 1994;121:200-6.

13. Yuan K-H, Maxwell S. On the Post Hoc Power in testing mean differences. J Educ Behav Stat 2005;30:141-67.

14. Agency for Healthcare Research and Quality. Methods Guide for Effectiveness and Comparative Effectiveness Reviews. AHRQ Publication No 10(14)-EHC063EF 2014;Rockville. Available onlile: https:// effectivehealthcare.ahrq.gov/topics/cer-methods-guide/ overview

15. Guyatt GH, Oxman AD, Kunz R, et al. GRADE guidelines 6. Rating the quality of evidence--imprecision. J Clin Epidemiol 2011;64:1283-93.

16. Shea BJ, Hamel C, Wells GA, et al. AMSTAR is a reliable and valid measurement tool to assess the methodological quality of systematic reviews. J Clin Epidemiol 2009;62:1013-20.

17. Viswanathan M, Berkman ND, Dryden DM, et al. Assessing Risk of Bias and Confounding in Observational Studies of Interventions or Exposures: Further Development of the RTI Item Bank. Rockville (MD): Agency for Healthcare Research and Quality (US); 2013.

18. Higgins JP, Altman DG, Gotzsche PC, et al. The Cochrane Collaboration's tool for assessing risk of bias in randomised trials. BMJ 2011;343:d5928.

19. Grading of Recommendations Assessment Development and Evaluation (GRADE) Workgin Group.

GRADE Handbook. Available online: http://gdt. guidelinedevelopment.org/central_prod/_design/client/ handbook/handbook.html\#h.fueh5iz0cor4

20. Guyatt GH, Oxman AD, Sultan S, et al. GRADE guidelines: 9. Rating up the quality of evidence. J Clin Epidemiol 2011;64:1311-6.

21. Gopal S, Hough D, Karcher K, et al. Risk of cardiovascular morbidity with risperidone or paliperidone treatment: analysis of 64 randomized, double-blind trials. J Clin Psychopharmacol 2013;33:157-61.

22. Yang FD, Wang XQ, Liu XP, et al. Sex difference in
QTc prolongation in chronic institutionalized patients with schizophrenia on long-term treatment with typical and atypical antipsychotics. Psychopharmacology (Berl) 2011;216:9-16.

23. Palanca-Maresca I, Ruiz-Antoran B, Centeno-Soto GA, et al. Prevalence and risk factors of prolonged corrected qt interval among children and adolescents treated with antipsychotic medications: a long-term follow-up in a realworld population. J Clin Psychopharmacol 2017;37:78-83.

24. Ozeki Y, Fujii K, Kurimoto N, et al. QTc prolongation and antipsychotic medications in a sample of 1017 patients with schizophrenia. Prog Neuropsychopharmacol Biol Psychiatry 2010;34:401-5.

25. Kimura G, Kadoyama K, Brown JB, et al. Antipsychoticsassociated serious adverse events in children: an analysis of the FAERS database. Int J Med Sci 2015;12:135-40.

26. Zink M, Kuwilsky A, Krumm B, et al. Efficacy and tolerability of ziprasidone versus risperidone as augmentation in patients partially responsive to clozapine: a randomised controlled clinical trial. J Psychopharmacol 2009;23:305-14.

27. Clozapine-Augmentation with ziprasidone or risperidone, a randomized, prospective trial. Available online: https:// ClinicalTrials.gov/show/NCT00224315

28. Lin CH, Kuo CC, Chou LS, et al. A randomized, double-blind comparison of risperidone versus lowdose risperidone plus low-dose haloperidol in treating schizophrenia. J Clin Psychopharmacol 2010;30:518-25.

29. Comparison of the efficacy and safety of risperidone versus risperidone plus low dose of haloperidol in the treatment of schizophrenia. Available online: https://ClinicalTrials. gov/show/NCT00998608

30. Harrigan EP, Miceli JJ, Anziano R, et al. A randomized evaluation of the effects of six antipsychotic agents on QTc, in the absence and presence of metabolic inhibition. J Clin Psychopharmacol 2004;24:62-9.

31. Reyes M, Buitelaar J, Toren P, et al. A randomized, doubleblind, placebo-controlled study of risperidone maintenance treatment in children and adolescents with disruptive behavior disorders. Am J Psychiatry 2006;163:402-10.

32. Haas M, Eerdekens M, Kushner S, et al. Efficacy, safety and tolerability of two dosing regimens in adolescent schizophrenia: double-blind study. Br J Psychiatry 2009;194:158-64.

33. Leonard CE, Freeman CP, Newcomb CW, et al. Antipsychotics and the risks of sudden cardiac death and all-cause death: cohort studies in medicaid and duallyeligible medicaid-medicare beneficiaries of five states. J 
Clin Exp Cardiolog 2013;Suppl 10:1-9.

34. Raschi E, Poluzzi E, Godman B, et al. Torsadogenic risk of antipsychotics: combining adverse event reports with drug utilization data across Europe. PLoS One 2013;8:e81208.

35. Jensen KG, Juul K, Fink-Jensen A, et al. Corrected QT changes during antipsychotic treatment of children and adolescents: a systematic review and meta-analysis of clinical trials. J Am Acad Child Adolesc Psychiatry 2015;54:25-36.

36. Germanò E, Italiano D, Lamberti M, et al. ECG parameters in children and adolescents treated with aripiprazole and risperidone. Prog Neuropsychopharmacol Biol Psychiatry 2014;51:23-7.

37. Pillay J, Boylan K, Carrey N, et al. First- and secondgeneration antipsychotics in children and young adults: systematic review update. Rockville (MD): Agency for Healthcare Research and Quality (US), 2017.

38. Stip E, Zhornitsky S, Moteshafi H, et al. Ziprasidone for psychotic disorders: a meta-analysis and systematic review of the relationship between pharmacokinetics, pharmacodynamics, and clinical profile. Clin Ther 2011;33:1853-67.

39. A study of risperidone long-acting injection versus oral antipsychotics in schizophrenia participants with a history of being poorly compliant with taking their medication. Available online: https://ClinicalTrials.gov/show/ NCT00256997

40. Safety Study of Sertindole Versus Risperidone Under Normal Conditions of Use. Available online: https:// ClinicalTrials.gov/show/NCT00856583

41. Janssen Pharmaceuticals I. Risperdal (risperidone tablets, oral solution, and orally disintegrating tablets). package insert 2017; Titusville, NJ.

42. DelBello MP, Versavel M, Ice K, et al. Tolerability of oral ziprasidone in children and adolescents with bipolar mania, schizophrenia, or schizoaffective disorder. J Child Adolesc Psychopharmacol 2008;18:491-9.

43. Miceli JJ, Tensfeldt TG, Shiovitz T, et al. Effects of Oral Ziprasidone and Oral Haloperidol on QTc interval in patients with Schizophrenia or Schizoaffective disorder. Pharmacotherapy 2010;30:127-35.

44. Camm AJ, Karayal ON, Meltzer H, et al. Ziprasidone and the corrected QT interval: a comprehensive summary of clinical data. CNS Drugs 2012;26:351-65.

45. Findling RL, Cavus I, Pappadopulos E, et al. Efficacy, long-term safety, and tolerability of ziprasidone in children and adolescents with bipolar disorder. J Child Adolesc Psychopharmacol 2013;23:545-57.
46. Findling RL, Cavus I, Pappadopulos E, et al. Ziprasidone in adolescents with schizophrenia: results from a placebocontrolled efficacy and long-term open-extension study. J Child Adolesc Psychopharmacol 2013;23:531-44.

47. Li XB, Tang YL, Zheng W, et al. QT Interval prolongation associated with intramuscular ziprasidone in Chinese patients: a case report and a comprehensive literature review with meta-analysis. Case Rep Psychiatry 2014;2014:489493.

48. Mischoulon D, Shelton RC, Baer L, et al. Ziprasidone augmentation of escitalopram for major depressive disorder: cardiac, endocrine, metabolic, and motoric effects in a randomized, double-blind, placebo-controlled study. J Clin Psychiatry 2017;78:449-55.

49. NCT00257166. Safety and efficacy of ziprasidone in children and adolescents with Bipolar I Disorder (Manic or Mixed). Available online: https://ClinicalTrials.gov/show/ NCT00257166

50. NCT00265382. Safety and tolerability of ziprasidone in adolescents with schizophrenia. Available online: https:// ClinicalTrials.gov/show/NCT00265382

51. NCT00633399. Ziprasidone Augmentation of SSRIs for patients with major depressive disorder (MDD) That do Not Sufficiently Respond to Treatment With SSRIs. Available online: https://ClinicalTrials.gov/show/ NCT00633399

52. NCT00748566. One-year trial of oral ziprasidone in patients with metabolic syndrome. Available online: https:/ClinicalTrials.gov/show/NCT00748566

53. NCT01113541. One-year trial of oral ziprasidone in bipolar patients with metabolic syndrome. Available online: https://ClinicalTrials.gov/show/NCT01113541

54. Strom BL, Eng SM, Faich G, et al. Comparative mortality associated with ziprasidone and olanzapine in real-world use among 18,154 patients with schizophrenia: The Ziprasidone Observational Study of Cardiac Outcomes (ZODIAC). Am J Psychiatry 2011;168:193-201.

55. Ou JJ, Xu Y, Chen HH, et al. Comparison of metabolic effects of ziprasidone versus olanzapine treatment in patients with first-episode schizophrenia. Psychopharmacology (Berl) 2013;225:627-35.

56. Simpson GM, Glick ID, Weiden PJ, et al. Randomized, controlled, double-blind multicenter comparison of the efficacy and tolerability of ziprasidone and olanzapine in acutely ill inpatients with schizophrenia or schizoaffective disorder. Am J Psychiatry 2004;161:1837-47.

57. Lindborg SR, Beasley CM, Alaka K, et al. Effects of intramuscular olanzapine vs. haloperidol and placebo on 
QTc intervals in acutely agitated patients. Psychiatry Res 2003;119:113-23.

58. Kishi T, Matsunaga S, Iwata N. Intramuscular olanzapine for agitated patients: A systematic review and metaanalysis of randomized controlled trials. J Psychiatr Res 2015;68:198-209.

59. Efficacy and Safety of Olanzapine in the Extended Treatment for Manic or Mixed Episode of Bipolar I Disorder. Available online: https://ClinicalTrials.gov/ show/NCT00266630

60. Findling RL, Correll CU, Nyilas M, et al. Aripiprazole for the treatment of pediatric bipolar I disorder: a 30-week, randomized, placebo-controlled study. Bipolar Disord 2013;15:138-49.

61. Findling RL, Robb A, Nyilas M, et al. A multiple-center, randomized, double-blind, placebo-controlled study of oral aripiprazole for treatment of adolescents with schizophrenia. Am J Psychiatry 2008;165:1432-41.

62. Marcus RN, Owen R, Kamen L, et al. A placebocontrolled, fixed-dose study of aripiprazole in children and adolescents with irritability associated with autistic disorder. J Am Acad Child Adolesc Psychiatry 2009;48:1110-9.

63. Breier A, Meehan K, Birkett M, et al. A double-blind, placebo-controlled dose-response comparison of intramuscular olanzapine and haloperidol in the treatment of acute agitation in schizophrenia. Archives of General Psychiatry 2002;59:441-8.

64. Katagiri H, Fujikoshi S, Suzuki T, et al. A randomized, double-blind, placebo-controlled study of rapid-acting intramuscular olanzapine in Japanese patients for schizophrenia with acute agitation. BMC Psychiatry 2013;13:20.

65. Katagiri H, Ono H, Fujikoshi S, et al. Placebocontrolled double-blinded study of olanzapine rapidacting intramusclar injection in Japanese patients with schizophrenia presenting psychomotor excitation. J New Remedies Clin 2012;61:30-41.

66. Meehan K, Zhang F, David S, et al. A double-blind, randomized comparison of the efficacy and safety of intramuscular injections of olanzapine, lorazepam, or placebo in treating acutely agitated patients diagnosed with bipolar mania. J Clin Psychopharmacol 2001;21:389-97.

67. Ono H, Fujikoshi S, Oka T, et al. Adouble-blind doseresponse study comparing rapid acting intramuscular olanzapine and placebo in agitated schizophrenia. J New Remedies Clin 2009;58:163-80.

68. Chan HY, Ree SC, Su LW, et al. A double-blind, randomized comparison study of efficacy and safety of intramuscular olanzapine and intramuscular haloperidol in patients with schizophrenia and acute agitated behavior. J Clin Psychopharmacol 2014;34:355-8.

69. Hsu WY, Huang SS, Lee BS, et al. Comparison of intramuscular olanzapine, orally disintegrating olanzapine tablets, oral risperidone solution, and intramuscular haloperidol in the management of acute agitation in an acute care psychiatric ward in taiwan. J Clin Psychopharmacol 2010;30:230-4.

70. Malone RP, Cater J, Sheikh RM, et al. Olanzapine versus haloperidol in children with autistic disorder: an open pilot study. J Am Acad Child Adolesc Psychiatry 2001;40:887-94.

71. Schoemaker J, Naber D, Vrijland P, et al. Longterm assessment of Asenapine vs. Olanzapine in patients with schizophrenia or schizoaffective disorder. Pharmacopsychiatry 2010;43:138-46.

72. A 6 Month Study to Compare the Metabolic Effects of Paliperidone ER and olanzapine in patients with schizophrenia. Available online: https://ClinicalTrials.gov/ show/NCT00645099

73. A study in relapse prevention of treatment-resistant depression. Available online: https://ClinicalTrials.gov/ show/NCT00958568

74. Katagiri H, Takita Y, Tohen M, et al. Efficacy and safety of olanzapine in the treatment of Japanese patients with bipolar I disorder in a current manic or mixed episode: a randomized, double-blind, placebo- and haloperidolcontrolled study. J Affect Disord 2012;136:476-84.

75. Trial of Olanzapine in Patients With Manic or Mixed Episode of Bipolar I Disorder. https://ClinicalTrials.gov/ show/NCT00129220

76. Intramuscular (IM) Olanzapine Versus IM Haloperidol Plus Lorazepam for Acute Agitation in Schizophrenia. Available online: https://ClinicalTrials.gov/show/ NCT00797277

77. A Study of Olanzapine in Patients With Schizophrenia. https://ClinicalTrialsgov/show/NCT00970281 2011.

78. Meehan KM, Wang H, David SR, et al. Comparison of rapidly acting intramuscular olanzapine, lorazepam, and placebo: a double-blind, randomized study in acutely agitated patients with dementia. Neuropsychopharmacology 2002;26:494-504.

79. Wright P, Birkett M, David SR, et al. Double-blind, placebo-controlled comparison of intramuscular olanzapine and intramuscular haloperidol in the treatment of acute agitation in schizophrenia. Am J Psychiatry 
2001;158:1149-51.

80. Citrome L. Asenapine for schizophrenia and bipolar disorder: a review of the efficacy and safety profile for this newly approved sublingually absorbed second-generation antipsychotic. Int J Clin Pract 2009;63:1762-84.

81. Hough DW, Natarajan J, Vandebosch A, et al. Evaluation of the effect of paliperidone extended release and quetiapine on corrected QT intervals: a randomized, double-blind, placebo-controlled study. Int Clin Psychopharmacol 2011;26:25-34.

82. Potkin SG, Preskorn S, Hochfeld M, et al. A thorough QTc study of 3 doses of iloperidone including metabolic inhibition via CYP2D6 and/or CYP3A4 and a comparison to quetiapine and ziprasidone. J Clin Psychopharmacol 2013;33:3-10.

83. A Study of the cataractogenic potential of seroquel and risperdal in the treatment of participants with schizophrenia or schizoaffective disorder. Available online: https://ClinicalTrials.gov/show/NCT00206102

84. Generalized Anxiety Disorder Adjunct Study. Available online: https://ClinicalTrials.gov/show/NCT00534599

85. Khan A, Atkinson S, Mezhebovsky I, et al. Extendedrelease quetiapine fumarate (quetiapine $\mathrm{XR}$ ) as adjunctive therapy in patients with generalized anxiety disorder and a history of inadequate treatment response: a randomized, double-blind study. Ann Clin Psychiatry 2013;25:E7-22.

86. Khan A, Atkinson S, Mezhebovsky I, et al. Extendedrelease quetiapine fumarate (quetiapine $\mathrm{XR}$ ) as adjunctive therapy in patients with generalized anxiety disorder and a history of inadequate treatment response: a randomized, double-blind study. Ann Clin Psychiatry 2014;26:3-18.

87. Gulisano M, Cali PV, Cavanna AE, et al. Cardiovascular safety of aripiprazole and pimozide in young patients with Tourette syndrome. Neurol Sci 2011;32:1213-7.

88. Owen R, Sikich L, Marcus RN, et al. Aripiprazole in the treatment of irritability in children and adolescents with autistic disorder. Pediatrics 2009;124:1533-40.

89. Marder SR, McQuade RD, Stock E, et al. Aripiprazole in the treatment of schizophrenia: safety and tolerability in short-term, placebo-controlled trials. Schizophr Res 2003;61:123-36.

90. Pigott TA, Carson WH, Saha AR, et al. Aripiprazole for the prevention of relapse in stabilized patients with chronic schizophrenia: a placebo-controlled 26-week study. J Clin Psychiatry 2003;64:1048-56.

91. Potkin SG, Saha AR, Kujawa MJ, et al. Aripiprazole, an antipsychotic with a novel mechanism of action, and risperidone vs placebo in patients with schizophrenia and schizoaffective disorder. Arch Gen Psychiatry 2003;60:681-90.

92. Kane JM, Carson WH, Saha AR, et al. Efficacy and safety of aripiprazole and haloperidol versus placebo in patients with schizophrenia and schizoaffective disorder. J Clin Psychiatry 2002;63:763-71.

93. Findling RL, Nyilas M, Forbes RA, et al. Acute treatment of pediatric bipolar I disorder, manic or mixed episode, with aripiprazole: a randomized, double-blind, placebocontrolled study. J Clin Psychiatry 2009;70:1441-51.

94. Marcus R, Khan A, Rollin L, et al. Efficacy of aripiprazole adjunctive to lithium or valproate in the long-term treatment of patients with bipolar I disorder with an inadequate response to lithium or valproate monotherapy: a multicenter, double-blind, randomized study. Bipolar Disord 2011;13:133-44.

95. Yoo HK, Joung YS, Lee JS, et al. A multicenter, randomized, double-blind, placebo-controlled study of aripiprazole in children and adolescents with Tourette's disorder. J Clin Psychiatry 2013;74:e772-80.

96. A multiple dose safety, tolerability and pharmacokinetics study in adult patients with schizophrenia following administration of aripiprazole IM Depot. Available online: https:/clinicaltrials.gov/ct2/show/NCT01870999?term= NCT01870999\&rank=1

97. Open-label, Extension Study of Aripiprazole Intramuscular Depot (OPC-14597, Lu AF41155) in Patients With Schizophrenia. Available online: https://clinicaltrials.gov/ ct2/show/NCT01683058? term=NCT01683058\&rank=1

98. Lazzerini PE, Laghi-Pasini F, Bertolozzi I, et al. Systemic inflammation as a novel QT-prolonging risk factor in patients with torsades de pointes. Heart 2017;103:1821-9.

99. Duchatelet S, Crotti L, Peat RA, et al. Identification of a KCNQ1 polymorphism acting as a protective modifier against arrhythmic risk in long-QT syndrome. Circ Cardiovasc Genet 2013;6:354-61.

100. Avery CL, Sitlani CM, Arking DE, et al. Drug-gene interactions and the search for missing heritability: a crosssectional pharmacogenomics study of the QT interval. Pharmacogenomics J 2014;14:6-13.

101. Rodday AM, Triedman JK, Alexander ME, et al. Electrocardiogram screening for disorders that cause sudden cardiac death in asymptomatic children: a metaanalysis. Pediatrics 2012;129:e999-1010.

102. Citrome L. Brexpiprazole for schizophrenia and as adjunct for major depressive disorder: a systematic review of the efficacy and safety profile for this newly approved antipsychotic - what is the number needed to treat, 
number needed to harm and likelihood to be helped or harmed? Int J Clin Pract 2015;69:978-97.

103. Trial to Evaluate the Effects of OPC-34712 on QT/ QTc in subjects with schizophrenia or schizoaffective disorder. Available online: https://ClinicalTrials.gov/show/ NCT01423916

104. Phase 1 study to assess the safety/tolerability of brexpiprazole as adjunctive therapy in elderly subjects with major depressive disorder. Available online: https:// ClinicalTrials.gov/show/NCT01670279

105. Otsuka Pharmaceutical Co. L. Rexulti (brexpiprazole) tablets package insert 2017; Rockville, MD: Available online: https://www.accessdata.fda.gov/drugsatfda_docs/ label/2017/205422s002lbl.pdf.

106.Wu CS, Tsai YT, Tsai HJ. Antipsychotic drugs and the risk of ventricular arrhythmia and/or sudden cardiac death: a nation-wide case-crossover study. J Am Heart Assoc 2015;4.

107. Weeke P, Jensen A, Folke F, et al. Antipsychotics and associated risk of out-of-hospital cardiac arrest. Clin Pharmacol Ther 2014;96:490-7.

108. Ray WA, Chung CP, Murray KT, et al. Atypical antipsychotic drugs and the risk of sudden cardiac death. N Engl J Med 2009;360:225-35.

109. Dias P, Penedones A, Alves C, et al. The role of disproportionality analysis of pharmacovigilance databases in safety regulatory actions: a systematic review. Curr Drug Saf 2015;10:234-50.

110.U.S. Department of Health and Human Services FaDA, Center for Drug Evaluation and Research (CDER), Center for Biologics Evaluation and Research (CBER). E14 Clinical Evaluation of QT/QTc Interval Prolongation and Proarrhythmic Potential for Non-Antiarrhythmic Drugs. Guidance for Industry 2017; Available online: http://www. fda.gov/Drugs/GuidanceComplianceRegulatoryInformati on/Guidances/default.htm

111. National Institute for Health and Care Excellence. Psychosis and schizophrenia in adults: prevention and management. Available online: https://wwwniceorguk/ guidance/CG178

112. National Institute for Health and Care Excellence. Bipolar disorder: assessment and management. NICE guidelines February 2016; Clinical guideline [CG185].

113. American Geriatrics Society Expert Panel on Postoperative Delirium in Older Adults. American Geriatrics Society abstracted clinical practice guideline for postoperative delirium in older adults. J Am Geriatr Soc 2015;63:142-50.
114.AstraZeneca Pharmaceuticals. Seroquel XR (quetiapine fumarate extended-release tablets) package insert 2017; Wilmington, DE: Available online: https://www.accessdata. fda.gov/drugsatfda_docs/label/2017/020639s065lbl.pdf

115.Pfizer. Geodon (ziprasidone) package insert 2017; New York, NY.

116. Shulman M, Miller A, Misher J, et al. Managing cardiovascular disease risk in patients treated with antipsychotics: a multidisciplinary approach. J Multidiscip Healthc 2014;7:489-501.

117. Shah AA, Aftab A, Coverdale J. QTc prolongation with antipsychotics: is routine ECG monitoring recommended? J Psychiatr Pract 2014;20:196-206.

118. Hashimoto Y, Tensho M. Effect of pharmacist intervention on physician prescribing in patients with chronic schizophrenia: a descriptive pre/post study. BMC Health Serv Res 2016;16:150.

119. Shen WK, Sheldon RS, Benditt DG, et al. 2017 ACC/ AHA/HRS Guideline for the evaluation and management of patients with syncope: executive summary: a report of the American College of Cardiology/American Heart Association Task Force on Clinical Practice Guidelines and the Heart Rhythm Society. Circulation 2017;136:e25-e59.

120. Bouvy JC, Koopmanschap MA, Shah RR, et al. The costeffectiveness of drug regulation: the example of thorough QT/QTc studies. Clin Pharmacol Ther 2012;91:281-8.

121. Beninger P, Ibara MA. Pharmacovigilance and Biomedical Informatics: A Model for Future Development. Clin Ther 2016;38:2514-25.

122. Black C, Tagiyeva-Milne N, Helms P, et al. Pharmacovigilance in children: detecting adverse drug reactions in routine electronic healthcare records. A systematic review. Br J Clin Pharmacol 2015;80:844-54.

123. Sarker A, Ginn R, Nikfarjam A, et al. Utilizing social media data for pharmacovigilance: A review. J Biomed Inform 2015;54:202-12.

124. Raschi E, Poluzzi E, Salvo F, et al. The Contribution of National Spontaneous Reporting Systems to Detect Signals of Torsadogenicity: Issues Emerging from the ARITMO Project. Drug Saf 2016;39:59-68.

Cite this article as: Aronow WS, Shamliyan TA. Effects of atypical antipsychotic drugs on QT interval in patients with mental disorders. Ann Transl Med 2018;6(8):147 doi: 10.21037/ atm.2018.03.17 


\section{Supplementary}

Table S1 Post-marketing reports of adverse effects associated with antipsychotics (from PharmaPendium.com)

\begin{tabular}{|c|c|c|c|}
\hline Drug & Adverse effects [case] & Gender [case] & Age [case] \\
\hline Risperidone & Electrocardiogram QT corrected interval prolonged [43] & Female [23], Male [20] & $20+[26],<20[4]$ \\
\hline $\begin{array}{l}\text { Ziprasidone } \\
\text { Hydrochloride }\end{array}$ & Torsade de pointes [83] & Female [61], Male [19] & $20+[57]$ \\
\hline $\begin{array}{l}\text { Ziprasidone } \\
\text { Hydrochloride }\end{array}$ & Electrocardiogram QT corrected interval prolonged [202] & Female [117], Male [63] & $20+[129],<20[22]$ \\
\hline Olanzapine & Torsade de pointes [54] & Female [32], Male [19] & $20+[51]$ \\
\hline Olanzapine & Electrocardiogram QT corrected interval prolonged [84] & Female [48], Male [26] & $20+[61],<20[6]$ \\
\hline Quetiapine & Torsade de pointes [90] & Female [68], Male [14] & $20+[79],<20[1]$ \\
\hline Quetiapine_ & Electrocardiogram QT corrected interval prolonged [56] & Female [28], Male [24] & $20+[39],<20[9]$ \\
\hline
\end{tabular}

Table S2 Mortality and hospitalization in 18,154 adults with schizophrenia treated with ziprasidone or olanzapine [crude results from the Ziprasidone Observational Study of Cardiac Outcomes (ZODIAC)]

\begin{tabular}{|c|c|c|c|c|c|}
\hline Outcome & $\begin{array}{l}\text { Risk with intervention } \\
\text { per } 1,000\end{array}$ & $\begin{array}{l}\text { Risk with comparator } \\
\text { per } 1,000\end{array}$ & $\begin{array}{l}\text { Relative measure of } \\
\text { association }\end{array}$ & $\begin{array}{l}\text { Quality } \\
\text { (GRADE) }\end{array}$ & Comments \\
\hline Non-suicide mortality, 1 year & 9 & 9 & RR $1.02(0.76,1.39)$ & Very low & No difference \\
\hline Cardiovascular mortality, 1 year & 0 & 1 & RR $0.38(0.10,1.41)$ & Very low & No difference \\
\hline Hospitalization, all-cause, 1 year & 151 & 109 & RR $1.39(1.29,1.50)$ & Low & $\begin{array}{l}\text { Favors } \\
\text { olanzapine }\end{array}$ \\
\hline Hospitalization, arrhythmia, 1 year & 1 & 0 & RR $1.75(0.51,5.98)$ & Very low & No difference \\
\hline $\begin{array}{l}\text { Hospitalization, myocardial infarction, } \\
1 \text { year }\end{array}$ & 1 & 1 & RR $1.18(0.53,2.64)$ & Very low & No difference \\
\hline
\end{tabular}

